\title{
Analysis of piston-pin lubrication considering the effects of structure deformation and cavitation*
}

\author{
Lin $\mathrm{BA}^{\dagger 1}$, Zhen-peng $\mathrm{HE}^{\dagger{ }^{\dagger 2}}$, Yue-hui LIU ${ }^{3}$, Gui-chang ZHANG ${ }^{2}$ \\ ( ${ }^{I}$ School of Materials Science and Engineering, Tianjin University, Tianjin 300072, China) \\ ( ${ }^{2}$ Aviation Institute of Automation, Civil Aviation University of China, Tianjin 300300, China) \\ $\left({ }^{3}\right.$ State Key Laboratory of Engines, Tianjin University, Tianjin 300072, China) \\ †E-mail: yeminghuangziji@163.com; hezhenpeng@tju.edu.cn
}

Received Apr. 14, 2014; Revision accepted Sept. 15, 2014; Crosschecked May 7, 2015

\begin{abstract}
Running conditions for piston pin boss bearing have become very severe due to the high combustion pressure and piston temperature increase over the past ten years. The aim of this paper was to analyze the friction and lubrication characteristic of piston pin boss bearings and a connecting rod small end bearing. This paper provided a comprehensive analysis of piston pin based on a multi-body dynamic model which considers the oil film cavitation and structure deformation. Effects of different lubrication models, pin structures, and thermal deformation on the lubrication were discussed. The lubrication characteristics and performance parameters including oil film pressure distribution, asperity contact pressure, the minimum oil film thickness, the maximum oil film pressure, and friction power loss were listed. The results showed that the minimum oil film thickness was very different and the maximum oil film pressure was nearly the same. A parabola profile of pin bore can reduce the wear to some extent, and a flare profile intensified wear in some places and caused the wear to be concentrated on a smaller area. Reducing the inner diameters will reduce the wear of the pin boss. However, in a realistic design of the pin, avoiding high inertial force of the piston system and satisfying the demand for reliability of the pin, increasing the inner diameters and reliability is a 'trade off' problem. A suitable design of the hollow diameter is very important. The results can provide guidance for the design of the pin boss bearing.
\end{abstract}

Key words: Gasoline engine, Piston-pin bearing, Thermo-elastic deformation, Asperity contact, Multi-body dynamic doi:10.1631/jzus.A1400105 Document code: A CLC number: TH133.31

\section{Introduction}

The piston pin joint is a key system in a reciprocating engine. It transmits forces between the piston and connecting rod while allowing the piston and connecting rod to rotate relatively independent of each other. Two different options for piston pin joint

\footnotetext{
Corresponding author

* Project supported by the National High-Tech R\&D Program (863 Program) of China (No. 2014AA0415011), the Research Fund for the Doctoral Program of Higher Education of China (No. 2014QD02S), the Research Fund for the Doctoral Program of Higher Education of China (No. 2013QD03S), and the Fundamental Research Funds for the Central Universities (No. 3122015C015), China

(10) ORCID: Lin BA, http://orcid.org/0000-0002-7753-8621; Zhen-peng HE, http://orcid.org/0000-0002-2418-3011

(C) Zhejiang University and Springer-Verlag Berlin Heidelberg 2015
}

design are presented in Fig. 1. In the floating pin design, the piston pin is clearance-fit into both the piston and connecting rod. The pin is free to rotate relative to both the piston and the connecting rod. In the alternative fixed-pin design, the pin is press-fit into the connecting rod and clearance-fit in the piston. For the floating pin design, the piston pin joint consists of a connecting rod small end bearing and two identical piston pin boss bearings. The piston pin joint operates under severe running conditions. High load in combination with high temperature and starved lubrication may constitute damage risk, like scuffing or seizure. For this reason, knowledge of the friction and lubrication of piston pin joint is essential to improve the piston pin joint design. 
In addition, the piston assembly, including the piston pin, piston skirt, and piston ring account for about $40 \%$ of all the engine frictional losses, and these losses account for approximately $20 \%$ of all engine losses (Andersson, 1991; Baker et al., 2012). Richardson (2000) found that the rod, piston ring, and piston skirt account for $18 \%-33 \%, 28 \%-45 \%$, and $25 \%-47 \%$, respectively. Previous studies mainly focused on the tribological characteristics of the ring and skirt. Few papers focused on the friction power loss and dynamic motion of the pin transient lubrication characteristics analysis due to the difficulty of establishing the model and the complex dynamic motion of the piston system.

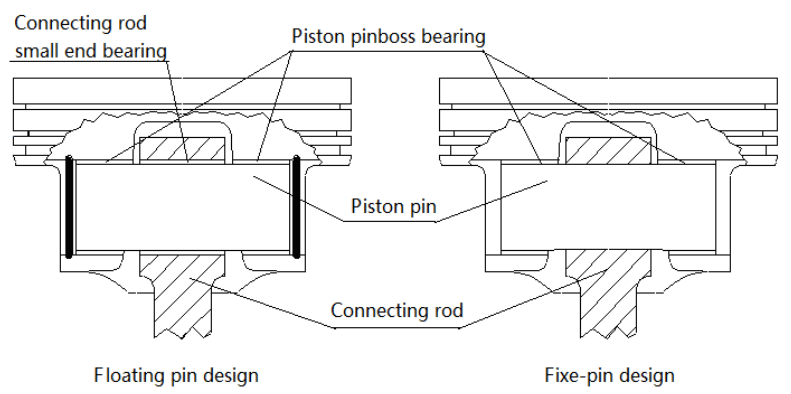

Fig. 1 Piston pin joint

The analysis of the piston pin joint is quite complicated, because the piston pin joint needs to be analyzed as a system of two bearings: the connecting rod small end bearing and the piston pin boss bearings, which are coupled through the rotation and elastic deformation of the pin. Unlike ordinary journal bearings, the pin rotation speed is unknown and difficult to acquire. Also, at high loads, particularly around combustion top dead center (TDC), it is expected that there will be significant bending of the pin and pin-boss, and asperity contact may occur in the hydrodynamic lubrication of the bearing. Consequently the elastic deformation and asperity contact of the bearing need to be considered in the bearing analysis.

The literature reviewed regarding lubrication and friction of the piston pin bearing revealed that very little has been published so far on this subject. Zhang et al. $(2003$; 2004) established an elaborate bench rig to simulate the operating conditions of a piston pin and studied its scuffing behavior by employing micrograph analysis of the bearing surface. They proposed a scuffing criterion stating that scuff- ing failure would occur when the maximum surface tangential traction is larger than the modified shear strength. Etsion et al. (2006) evaluated the effect of various surface engineering methods on the tribological performance of a piston pin on a test rig. Takiguchi et al. (1996) and Suhara et al. (1997) dealt experimentally with friction and lubrication characteristics of the small end connecting rod bearing and the piston pin boss bearing, respectively. They developed a device to measure the friction force in these bearings. Clark et al. (2009) measured piston pin surface temperature and pin rotation speed with a telemetry systems equipped with inductively powered transducers during an engine test. Takeuchi (2011) observed the behavior of the oil film formation and the cavitation between the piston pin and the pin boss with an ultrasonic technique in a real engine operating under low rotational speed. A mixed lubrication model based on spectral elasto-hydrodynamic (EHD) and nonlinear Greenwood and Trip statistical asperity contact formulation was developed by Fridman et al. (2006) for a heavy duty diesel engine piston pin joint. This explored the effect of connecting rod small end bushing geometry and pin bore geometry on the asperity contact pressure and heat generated in a heavy duty piston pin joint. Ligier and Ragot (2005) proposed a refined contact model implemented in a simple hydrodynamic lubrication program for the piston pin. The hydrodynamic load carrying capacity of the connecting rod small end bearing is given by the semi-empirical Hayes relationship, and the wedge oil effect was neglected. Shi (2011) performed a comprehensive numerical analysis of a floating piston pin by using FLARE, lubrication analysis software developed for the GM Company. A mass-conserving elastohydrodynamic lubrication (EHL) algorithm is implemented in the mixed lubrication model. He et al. (2013) analyzed the effect of the cavitation on the lubrication of journal-bearing with cavitation model without surface roughness and inter-asperity cavitation model. Nishikawa (2012) analyzed the oil film thickness in the piston pin boss bearing to reduce piston pin noise of a semi-floating piston. Wang et al. (2011) built a mixed lubrication model of a piston pin bearing based on the unified Reynolds equation and the fast Fourier transform (FFT) method and applied it to a diesel engine. They concluded that viscosity-pressure played a significant role in the oil film characteristic and the piston pin orbit. 
In this study, the multi-body dynamic model of the piston crank-slider mechanism was built to analyze the lubrication for the piston pin joint. Flexible body parts such as piston, liner, pin, and connecting rod were used in the model. An EHD lubrication model including cavitation and asperity contact formulation was also introduced in the two interfaces: piston pin boss bearings and connecting rod small end bearing. The hydrodynamic and asperity contact interactions between the pin and the two bearings were obtained. The simulated piston pin boss bearing wear pattern was compared with the failure mode of the pin bore done by the experiment. Other bearing characteristics, such as power loss, oil film pressure distribution, and asperity contact pressure, were also listed. Apart from the elastic deformation, the thermal deformation of the piston simulated by the finite element method (FEM) was also added to the lubrication model, and all the results were compared with previous results obtained without the thermal deformation. To optimize the wear of the pin boss bearing, the geometry of piston pin bore was modified. All the analyses will provide guidance for the design of the piston pin.

\section{Theory analysis}

\subsection{Condensation of degrees of freedom}

The governing equation describing the piston crank-slider system dynamics can be written as

$$
M \ddot{u}+C \dot{\boldsymbol{u}}+\boldsymbol{K u}=\boldsymbol{F},
$$

where $\boldsymbol{u}$ represents the degrees of freedom (DOFs) of the system, $\boldsymbol{M}$ is the mass matrix of the system, $\boldsymbol{C}$ is the damping matrix, $\boldsymbol{K}$ is the stiffness matrix, and $\boldsymbol{F}$ is the load vector.

The total amount of time needed for the computation is significantly influenced by the number of DOFs for each body. To solve the equation efficiently, the number of DOFs has to be reduced while keeping sufficient system dynamic behavior. The DOFs $\boldsymbol{u}$ can be divided into internal DOFs $\boldsymbol{u}_{\mathrm{i}}$ and retained DOFs $\boldsymbol{u}_{\mathrm{r}}$. Retained DOFs are those have external connections to other elements which are reserved, such as joints and force. Eq. (1) can be rewritten as

$$
\begin{aligned}
& {\left[\begin{array}{ll}
\boldsymbol{M}_{\mathrm{ii}} & \boldsymbol{M}_{\mathrm{ir}} \\
\boldsymbol{M}_{\mathrm{ri}} & \boldsymbol{M}_{\mathrm{rr}}
\end{array}\right]\left\{\begin{array}{l}
\ddot{\boldsymbol{u}}_{\mathrm{i}} \\
\ddot{\boldsymbol{u}}_{\mathrm{r}}
\end{array}\right\}+\left[\begin{array}{ll}
\boldsymbol{C}_{\mathrm{ii}} & \boldsymbol{C}_{\mathrm{ir}} \\
\boldsymbol{C}_{\mathrm{ri}} & \boldsymbol{C}_{\mathrm{rr}}
\end{array}\right]\left\{\begin{array}{c}
\dot{\boldsymbol{u}}_{\mathrm{i}} \\
\dot{\boldsymbol{u}}_{\mathrm{r}}
\end{array}\right\}} \\
& +\left[\begin{array}{ll}
\boldsymbol{K}_{\mathrm{ii}} & \boldsymbol{K}_{\mathrm{ir}} \\
\boldsymbol{K}_{\mathrm{ri}} & \boldsymbol{K}_{\mathrm{rr}}
\end{array}\right]\left\{\begin{array}{l}
\boldsymbol{u}_{\mathrm{i}} \\
\boldsymbol{u}_{\mathrm{r}}
\end{array}\right\}=\left[\begin{array}{l}
\boldsymbol{F}_{\mathrm{i}} \\
\boldsymbol{F}_{\mathrm{r}}
\end{array}\right] .
\end{aligned}
$$

According to the Craig-Bampton method (Craig and Bampton, 1968), the interior DOFs $\boldsymbol{u}_{\mathrm{i}}$ can be substituted by the range of mode number and the retained DOF can substitute the internal DOF. The static modes and fixed-boundary normal modes are combined to account for the influence of the non-zero values of retained DOFs $\boldsymbol{u}_{\mathrm{r}}$ on DOFs $\boldsymbol{u}_{\mathrm{i}}$.

The orders of mode are less than the number of DOF. The range of mode number and the retained DOF can substitute for the internal DOF. It can be written as

$$
\boldsymbol{u}=\left\{\begin{array}{c}
\boldsymbol{u}_{\mathrm{i}} \\
\boldsymbol{u}_{\mathrm{r}}
\end{array}\right\}=\left[\begin{array}{cc}
\boldsymbol{U} & \boldsymbol{T} \\
0 & \boldsymbol{I}
\end{array}\right]\left\{\begin{array}{c}
\boldsymbol{\alpha} \\
\boldsymbol{u}_{\mathrm{r}}
\end{array}\right\}=\boldsymbol{\varphi}\left\{\begin{array}{c}
\boldsymbol{\alpha} \\
\boldsymbol{u}_{\mathrm{r}}
\end{array}\right\},
$$

where $\boldsymbol{\alpha}$ is the modal participation factor, $\boldsymbol{\alpha}=$ $\left[\begin{array}{cccc}\alpha_{1} & \alpha_{2} & \cdots & \alpha_{j}\end{array}\right]^{\mathrm{T}} ; \boldsymbol{\varphi}=\left[\begin{array}{cc}\boldsymbol{U} & \boldsymbol{T} \\ 0 & \boldsymbol{I}\end{array}\right]$ is the reduction matrix, and $\boldsymbol{U}, \boldsymbol{T}$, and $\boldsymbol{I}$ are one part of matrix $\boldsymbol{\varphi}$.

Eq. (3) is substituted into Eq. (2). Then, the dynamic equation can be written as

$$
\bar{M}\left\{\begin{array}{c}
\ddot{\alpha} \\
\ddot{u}_{\mathrm{r}}
\end{array}\right\}+\overline{\boldsymbol{C}}\left\{\begin{array}{c}
\dot{\boldsymbol{\alpha}} \\
\dot{\boldsymbol{u}}_{\mathrm{r}}
\end{array}\right\}+\overline{\boldsymbol{K}}\left\{\begin{array}{c}
\boldsymbol{\alpha} \\
\boldsymbol{u}_{\mathrm{r}}
\end{array}\right\}=\overline{\boldsymbol{F}}
$$

Due to the high non-linearity of interaction between piston pin and bearing, the equations have to be solved in the time domain. In each time step, the equilibrium has to be fulfilled for the entire system. To maximize numerical stability, the direct implicit integration method was used.

\subsection{Bearing lubrication model}

The piston pin is supported by the oil film hydrodynamic pressure in the pin boss bearings and connecting rod small end bearing. The hydrodynamic (HD) lubrication model can be employed to solve the hydrodynamic force acting on the piston pin due to the pressure developed in the oil film. The primary equation to be solved for lubrication analysis is the Reynolds equation. In its basic form the equation is 


$$
\begin{aligned}
& \frac{\partial}{\partial x}\left(\frac{h^{3}}{\eta} \frac{\partial p}{\partial x}\right)+\frac{\partial}{\partial z}\left(\frac{h^{3}}{\eta} \frac{\partial p}{\partial z}\right) \\
& =6\left(u_{1}+u_{2}\right) \frac{\partial h}{\partial x}+12 \frac{\partial(h)}{\partial t},
\end{aligned}
$$

where $h$ denotes the oil film thickness, $\eta$ is the oil viscosity, $p$ is the oil film pressure, and $u_{1}$ and $u_{2}$ are the surface velocities of bearing and the journal, respectively. $u_{1}$ is 0 for the piston pin boss bearing. For the connecting rod small end bearing $u_{1}$ can be obtained by multiplying the angular speed of the connecting rod by its radius. $x$ and $z$ are the horizontal and axial coordinates of the bearing.

The HD bearing model does not consider the deflections of bearing shell, which may have a significant effect on bearing behavior in some cases. The EHD lubrication model considers more factors than the HD model, such as the roughness of bearing surface, asperity contact, and cavitation. In addition, the bearing and pin are assumed to be elastic rather than rigid. Consequently the EHD model can offer a more realistic prediction than the HD model. To evaluate the effect of the surface roughness, the average Reynolds equation between the piston and pin is used, according to the average flow model that was put forward by Patir and Cheng (1978). When the effects of surface roughness on the lubrication and cavitation are considered, the governing equation can be written as

$$
\begin{aligned}
& \frac{\partial}{\partial x}\left(\phi_{x} \frac{h^{3}}{\eta} \frac{\partial p}{\partial x}\right)+\frac{\partial}{\partial z}\left(\phi_{z} \frac{h^{3}}{\eta} \frac{\partial p}{\partial z}\right) \\
& =6\left(u_{1}+u_{2}\right) \frac{\partial}{\partial x}\left(h+\sigma \phi_{\mathrm{s}}\right)+12 \frac{\partial(h)}{\partial t}
\end{aligned}
$$

where $\phi_{x}$ and $\phi_{z}$ are the pressure flow factors, and $\phi_{\mathrm{s}}$ is the shear flow factor. The three flow factors are used for consideration of the effect of surface roughness on the hydrodynamic flow and pressure generation. $\sigma$ is the composite root mean square summit roughness.

When the deformation of the pin boss bearing is added to the lubrication model, the oil film thickness between the pin boss and pin is composed of the radial clearance, deformation of the piston, and misalignment of the pin. Under these conditions, the oil film thickness appears as

$$
h=c-e_{x} \cos \theta-e_{z} \sin \theta+\delta^{\prime},
$$

where $c$ is the nominal bearing clearance, $e_{x}$ and $e_{z}$ are the pin deformations in the $x$ and $z$ directions, respectively, $\theta$ is the angle along the bearing circumference direction, and $\delta^{\prime}$ is the radical deformation of the bearing.

In addition to the hydrodynamic pressure, asperity contact pressure also plays an important role in bearing loading capacity in the EHD model. Greenwood and Williamson (1966) related the asperity contact model to statistical values of the summit roughness. The asperity contact pressure is given by

$$
\begin{aligned}
& P_{\text {asp }}=\frac{16 \sqrt{2} \pi}{15}\left(\sigma \beta^{\prime} \eta^{\prime}\right)^{2} \sqrt{\frac{\sigma}{\beta^{\prime}}} E^{\prime} F_{5 / 2}(H), \\
& F_{5 / 2}(H)= \begin{cases}4.486 \times 10^{-5}(4-H)^{6.804}, & H<4, \\
0, & H \geq 4,\end{cases} \\
& K=\frac{16 \sqrt{2} \pi}{15}\left(\sigma \beta^{\prime} \eta^{\prime}\right)^{2} \sqrt{\frac{\sigma}{\beta^{\prime}},}
\end{aligned}
$$

where $P_{\text {asp }}$ is the asperity contact pressure, $H=h / \sigma$ denotes the oil film thickness ratio, $F_{5 / 2}(H)$ is the form function indicates whether asperity happens or not, $\beta^{\prime}$ is the mean summit radius of the roughness, $\eta^{\prime}$ is the asperity density, $E^{\prime}=\left[\left(1-v_{1}^{2}\right) / E_{1}+\left(1-v_{2}^{2}\right) / E_{2}\right]^{-1}$ is the composite elastic modulus, where $E_{1}, E_{2}$, and $v_{1}, v_{2}$ are the Young's moduli and Poisson's ratios of the contact surface. Since the parameters $\eta^{\prime}, \beta^{\prime}$, and $\sigma$ are difficult to be specific, it is more convenient to use the so-called elastic factor $K$ for parameterization of the contact model, where $K$ usually varies in the range of $0.003-0.03$.

Oil viscosity decreases when temperature increases. The influence of temperature and pressure on the oil viscosity is assumed from Vogel's and Barus' formula, thus (Xu, 2005):

$$
\mu=\mu_{0}\left(T_{\mathrm{o}}\right) \mathrm{e}^{\alpha^{\prime} P},
$$

where $T_{\mathrm{o}}$ is the temperature of the oil film, $P$ is the fluid pressure, $\mu_{0}$ is the viscosity at atmospheric pressure, and $\alpha^{\prime}$ is the index of the viscosity variation with pressure in Pascal.

\section{Model description and analysis process}

\subsection{FEM model of the system}

In this study, an inline 4-cylinder automobile purpose gasoline engine was taken as the basis in the 
simulation. The engine specifications of the engine and operating conditions are tabulated in Table 1.

Pressure curves are tested from experiment which collects the pressure signal of many cycles and calculates the average (Fig. 2).

Table 1 Engine specifications

\begin{tabular}{lc}
\hline \multicolumn{1}{c}{ Item } & Description \\
\hline Engine type & 4-cylinder \\
& gasoline engine \\
Bore $(\mathrm{mm})$ & 74.7 \\
Stroke $(\mathrm{mm})$ & 84.7 \\
Connecting rod length $(\mathrm{mm})$ & 127 \\
Connecting rod mass, $m_{\mathrm{rod}}(\mathrm{g})$ & 389 \\
Compression ratio & 10.2 \\
Peak combustion pressure $(\mathrm{MPa})$ & 8 \\
Maximum power $(\mathrm{kW})(6000 \mathrm{r} / \mathrm{min})$ & 82 \\
Maximum torque $(\mathrm{N} \cdot \mathrm{m})(3600 \mathrm{r} / \mathrm{min})$ & 142 \\
Maximum speed $(\mathrm{r} / \mathrm{min})$ & 6500 \\
Radial skirt-liner clearance $(\mu \mathrm{m})$ & 20 \\
\hline
\end{tabular}

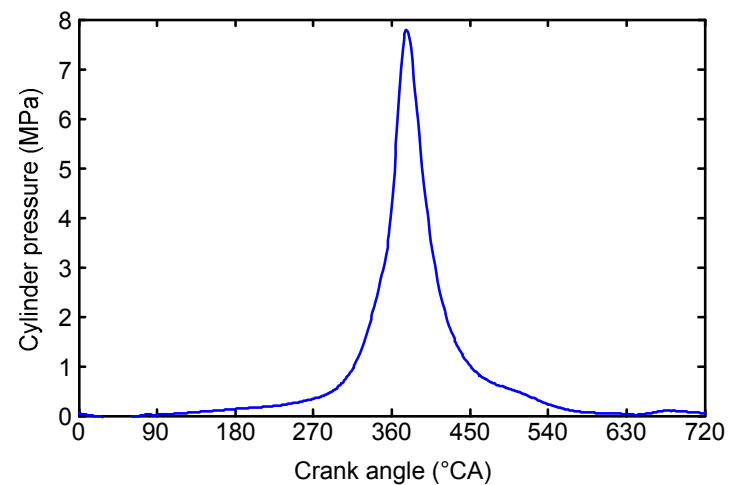

Fig. 2 Cylinder pressure curve

The multi-body dynamic model of the piston crank-slider mechanism consists of three parts: a piston, a piston pin and a connecting rod, and three bearings. The piston and pin geometric parameters are shown in Table 2. Two identical pin boss bearings and a connecting rod small end bearing are shown in Fig. 3. Due to the high load from gas pressure in the cylinder, the piston pin bore and piston pin experience substantial deformation. The piston pin bending and ovalization is believed to be an important contributor to the local contact concentration, and thus friction and surface damage of the bearings. For this reason, the bearing surfaces and journals are assumed to be elastic. That is, the piston, piston pin, and connecting rod have to be modeled as a flexible body.

Table 2 Piston and pin geometric parameters

\begin{tabular}{lc}
\hline \multicolumn{1}{c}{ Parameter } & Value \\
\hline Piston diameter $(\mathrm{mm})$ & 74.7 \\
Piston height $(\mathrm{mm})$ & 45.3 \\
Compression height $(\mathrm{mm})$ & 27 \\
Piston mass, $m_{\text {piston }}(\mathrm{g})$ & 195 \\
Pin outer diameter, $D(\mathrm{~mm})$ & 18 \\
Pin inner diameter, $d(\mathrm{~mm})$ & 11 \\
Pin length $(\mathrm{mm})$ & 50 \\
Pin mass $(\mathrm{g})$ & 62 \\
\hline
\end{tabular}

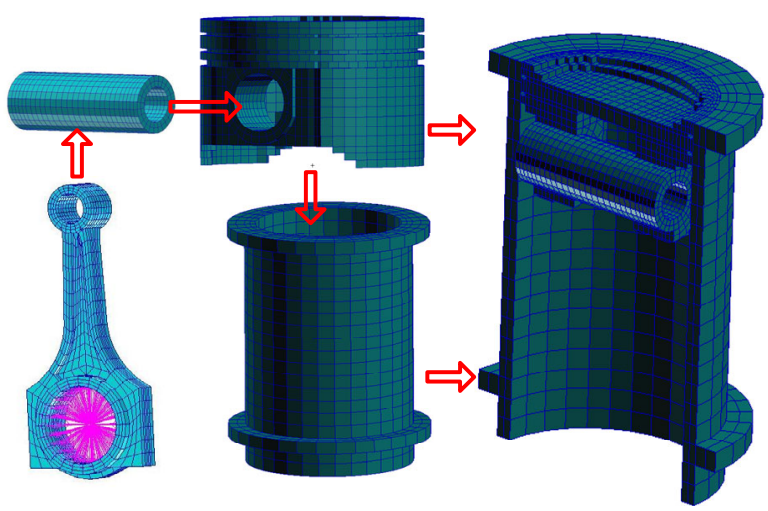

Fig. 3 FEM model of the piston, piston pin, and connecting rod

The three parts are all meshed with an 8-node Hex element in Nastran code which is based on the FEM. The piston has 7089 nodes and 5521 elements, the piston pin has 2090 nodes and 1442 elements, and the connecting rod has 9097 nodes and 7206 elements. Multi-point-constrain is employed in the connecting rod big end to define its circular motion. For piston boss bearings, the pin bore and pin have the same mesh topology at their interface. For the connecting small end bearing, the small end hole and pin also have the same mesh topology at their interface. The flexible piston, piston pin, and connecting rod are shown in Fig. 3.

\subsection{Model of the bearing}

To carry out the pin boss lubrication, the lubrication parameters of the pin boss and the small end bearing are very important. In this study, the detailed parameters of the pin boss bearing and the small end bearing are given in Table 3 and Table 4, respectively. 
Table 3 Parameters of the pin boss bearing

\begin{tabular}{lc}
\hline \multicolumn{1}{c}{ Parameter } & Value \\
\hline Bearing width $(\mathrm{mm})$ & 14 \\
Radial clearance $(\mu \mathrm{m})$ & 10 \\
Roughness of the pin $(\mu \mathrm{m})$ & 0.6 \\
Roughness of the pin bore $(\mu \mathrm{m})$ & 0.7 \\
Oil type & SAE10W/40 \\
Oil temperature $\left({ }^{\circ} \mathrm{C}\right)$ & 120 \\
\hline
\end{tabular}

Table 4 Parameters of the small end bearing

\begin{tabular}{lc}
\hline \multicolumn{1}{c}{ Parameter } & Value \\
\hline Bearing width $(\mathrm{mm})$ & 18 \\
Radial clearance $(\mu \mathrm{m})$ & 12 \\
Roughness of the small end hole $(\mu \mathrm{m})$ & 0.0 .25 \\
Oil type & SAE $10 \mathrm{~W} / 40$ \\
Oil temperature $\left({ }^{\circ} \mathrm{C}\right)$ & 120 \\
\hline
\end{tabular}

The modal calculation for the large structure is usually time-consuming. To reduce the amount of time needed for computation, the FEM models are condensed according to the Craig-Bampton method. The component mode synthesis method (CMS) is the method that only needs the participation of some particular modes in the simulation. This can reduce the calculation time. If the loading frequency is close to a natural frequency of the structure, then the corresponding modal participates significantly. In this study, only the first ten order modes are calculated for the piston. In fact, the frequency of the piston is very high, its frequency has little effect on the vibration, and its modes are the free mode. The first twenty order modes are calculated for the piston pin according to the interested frequency of the pin, and the free modes are also used to establish the multi-body dynamic mode. The first six mode shapes of the piston pin are shown in Appendix A. When we write the Nastran damp file for the mode reduction, we only extract two translational DOFs and one rotational DOF. The translational DOF along the pin hole is constrained.

For the pin boss bearing, which couples the pin bore with the pin, the pin rotates at angular speed $\varpi_{\mathrm{p}}$ in the fixed pin bore. The $x$ and $y$ translational DOFs of 120 nodes on the pin bore surface are reserved as interface nodes which are used for connection with the pin. These nodes lie in five sections along the axis direction of the pin bore and each section has 24 nodes along the circumferential direction. In addition, the $z$ translational DOFs of nine nodes on the top of the piston are also reserved for applying gas force. The reserved nodes of the piston are shown in Fig. 4.
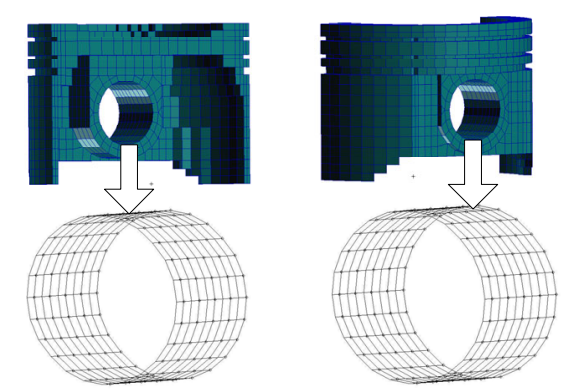

Fig. 4 Retain nodes of the pin boss bearing after CMS

For the connecting rod small end bearing, the pin rotates at angular speed $\varpi_{\mathrm{p}}$ and the connecting rod small end hole rotates at angular speed $\varpi_{\mathrm{c}}$. Similar to the piston pin bore, the connecting rod small end holes also have five sections of nodes along the axis direction and each section has 24 nodes along the circumferential direction.

The finite difference method (FDM) is used to calculate the oil film hydrodynamics. The oil film thickness is substituted into the Reynolds equation, and the oil film pressure can be obtained by solving the equation. The oil film pressure works as the exciting force that leads the journal to be misaligned and the pin boss to deform. Thus, the theory of the FDM couples with the FEM. The hydrodynamic pressure profile calculated from the Reynolds equation contains sharp gradients resulting from the eccentric position of the piston pin. A fine FDM mesh density must be used for the oil film hydrodynamics, while a coarse FEM mesh density can be used for bearing structure to reduce the amount of computation. The oil film hydrodynamics at each crank angle is a function of the bearing clearance gap due to the piston pin position and bearing structural deformation. This information is transferred from the coarse mesh of the structure to the fine mesh of the oil film by an interpolation technique (Fig. 5). After calculating the oil film hydrodynamics, the results are transferred back to the coarse structure mesh for structural dynamic computations. The oil film has a 21 by 120 FDM mesh density. 


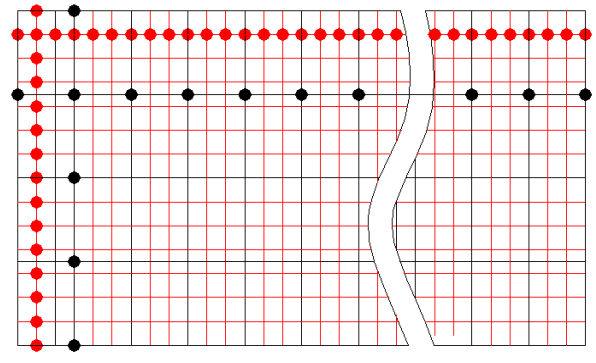

Fig. 5 Interpolation method for the coupled of FEM and lubrication

\subsection{Deformation analysis}

\subsubsection{Loads for mechanical distortion}

The overall deformation of the piston consists of mechanical distortion and thermal distortion. The mechanical distortion is determined by the method used by Littlefair et al. (2014). The loads applied for the estimation of the piston's mechanical distortion are as follows: (1) gas load applied on the piston crown; (2) piston inertial force due to the primary accelerative motion; and (3) piston side force acting orthogonal to the skirt surface. As shown in (Littlefair et al., 2014), these loads actually cause the skirt to deform, which in turn affect the pin boss. In this study, the multi-body dynamic motion model is established with the solid model. The gas load is simplified as an average load that is applied on the nodes of the piston top surface. The initial force is applied on the mass center with multi-point constraint. A piston side force acting orthogonal to the skirt surface is produced by the oil film pressure, and it will cause the piston skirt to deform. When the piston moves along the cylinder, the oil film will produce a secondary motion of the piston.

The cylinder gas force $F_{\mathrm{g}}$ acts on the top surface of piston. It is obtained by an experiment which collects the pressure signal of 100 cycles and calculates the average. The inertial force $F_{\mathrm{j}}$ of the piston assembly is defined as

$$
F_{\mathrm{j}}=-\left[m_{\text {piston }}+\left(m_{\text {rod }} l_{\mathrm{b}} / l\right)\right] R w^{2}[\cos \alpha+\lambda \cos (2 \alpha)]
$$

where $l_{\mathrm{b}}$ is the length of the connecting rod from mass center to big end, $l$ is the length of the connecting rod, $R$ is the radius of the crank-pin, $w$ is the angular velocity of the crankshaft, and $\lambda$ is the connecting rod ratio, $R / l$.
When the cylinder pressure $p_{\mathrm{g}}$ acts on the piston head, it can be simplified as the concentrated force, which is written as

$$
F_{\mathrm{g}}=p_{\mathrm{g}} \frac{\pi}{4} D^{\prime 2}
$$

where $D^{\prime}$ is the diameter of the cylinder.

The force $F_{\mathrm{L}}$ along crank pin can be divided into the force along the tangential direction $F_{\mathrm{T}}$ and the force along normal direction $F_{\mathrm{N}}$ (Fig. 6a). The pin boss bearing load at one side of the piston can be written as

$$
F_{\mathrm{L}}=F / \cos \beta=\left(F_{\mathrm{g}}+F_{\mathrm{j}}\right) / \cos \beta
$$

The piston side force $\left(F_{\mathrm{p}}\right)$ acting orthogonal to the skirt surface is the oil film force. It is produced by the side force, and it appears as

$$
F_{\mathrm{p}}=F \tan \beta .
$$

\subsubsection{Pin and pin bore deflections}

Theoretically, the longitude deflection of the pin and pin bore can both lead to misalignment in the pin boss bearing. The effect of pin bending on the pin boss bearing behavior is discussed by Shi (2011) and it is believed to be an important contributor to the local contact concentration, and thus friction and surface damage of the bearing. But the effect of pin bore deflection has not been discussed thoroughly so far, especially the deflection caused by thermal expansion.

When the force acts on the piston pin, the pin will deform as shown in Fig. 7. The following correlation, which was given by Robinson (1965), can be used to calculate the pin bending deflection.

$$
\begin{aligned}
f_{\text {pin }} & =\left(1-\frac{b}{2 a}\right) F_{\max } \frac{a^{3}}{48 E J}, \\
J & =(\pi / 64)\left(D^{4}-d^{4}\right),
\end{aligned}
$$

where $a$ is the distance between the center of front pin bore and rear pin bore, $b$ is the width of the connecting rod small end, $F_{\max }$ is the maximum gas force on the piston, $E$ is the Young's modulus, and $J$ is the 
flexural moment of inertia of the pin cross section. Then the angular misalignment caused by pin bending is obtained as $0.065^{\circ}$.
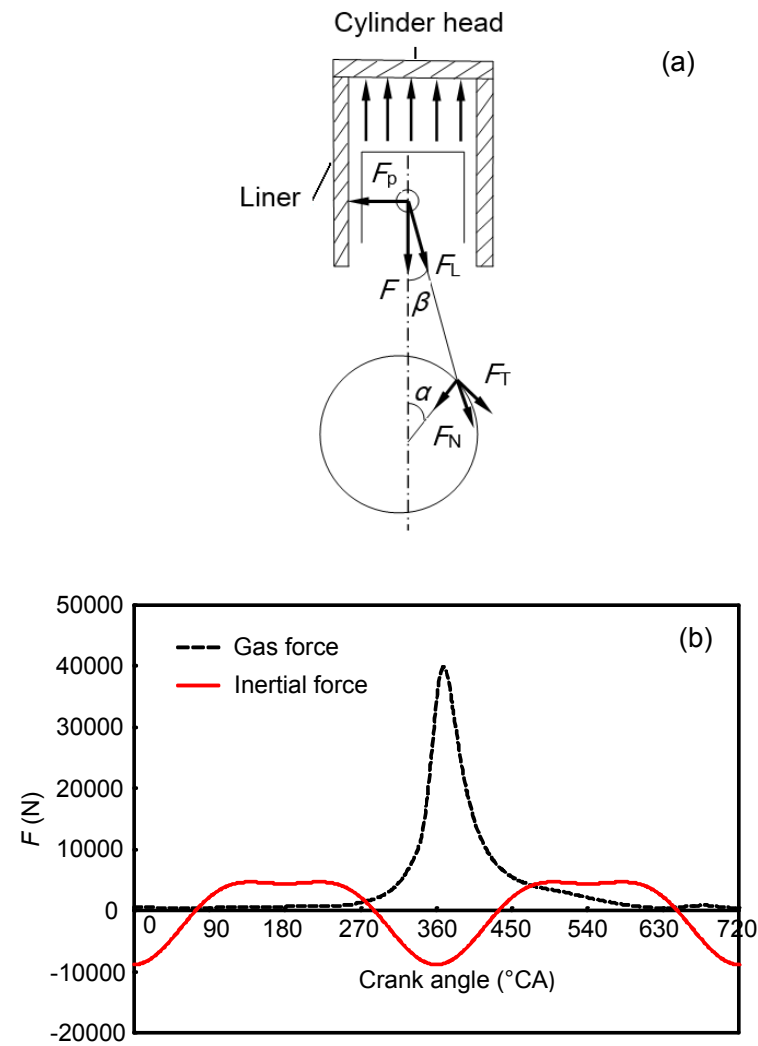

Fig. 6 Connecting rod and force analysis on crank-pin and liner

(a) Load schematic of the connecting rod; (b) Gas force and inertial force in one cycle

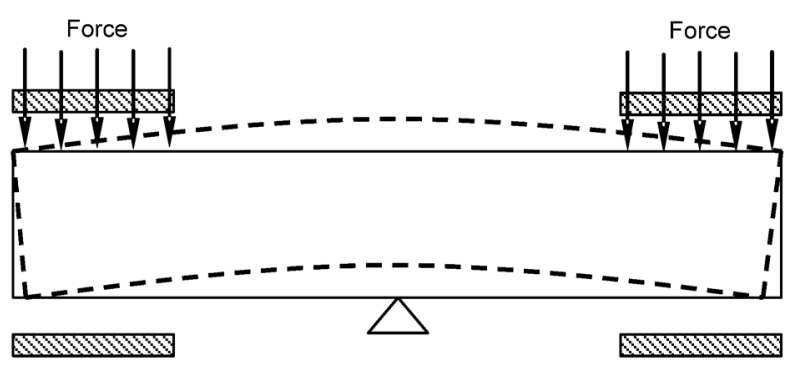

Fig. 7 Pin deformation under the cylinder pressure

Structural analysis is performed on the piston assembly to investigate the effect of mechanical deformation on bearing misalignment by applying peak firing pressure and inertial load and side force at the time that the piston approaches TDC during the ex- pansion process. Pin and pin bore contact is considered in the model. Fig. 8 shows the mechanical deformation of the piston, which is scaled 200 times. Pin boss deflection toward inner side, which leads to bearing misalignment, was observed due to the peak loading at the inner side edge of the pin boss. The peak loading is caused by piston pin bending.
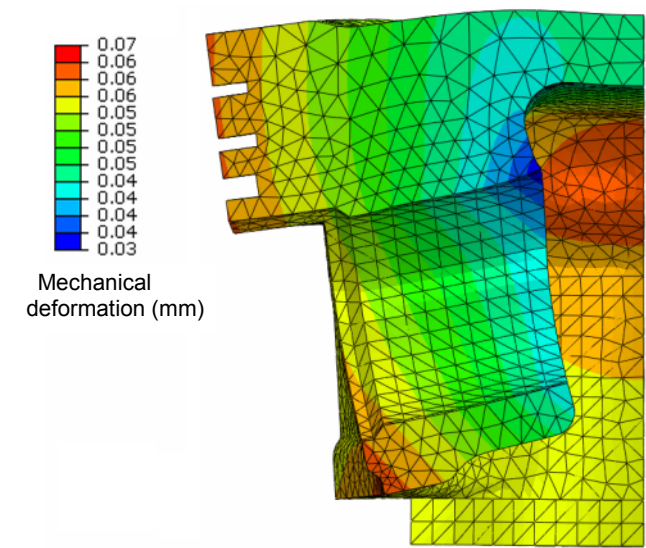

Fig. 8 Mechanical deformation of pin bore (scaled 200 times)

\subsection{Thermal deformation}

The temperature and the heat transfer coefficient of the cylinder are simulated by GT-POWER which establishes the model with four cylinders to obtain the performance of the engine. The transient temperature and transfer coefficient are shown in Fig. 9. Yuan et al. (2005) found that temperature fluctuation existed in $2 \mathrm{~mm}$ thickness of the piston top surface. So the temperature of the piston is static. When we solve the temperature of the piston, the average temperature and average heat transfer coefficients are iterated to the second heat transfer boundary condition. The average gas temperature and heat transfer coefficients for the piston top are determined by using engine cycle simulation code, which can be written as

$$
\begin{gathered}
T_{\mathrm{gm}}=\frac{\int_{-360}^{360} \beta_{\mathrm{g}} T_{\mathrm{g}} \mathrm{d} \varphi}{720 \beta_{\mathrm{gm}}}-273 \\
\beta_{\mathrm{gm}}=\frac{1}{720} \int_{-360}^{360} \beta_{\mathrm{g}} \mathrm{d} \varphi \\
\frac{\partial T}{\partial \tau}=\frac{\partial}{\partial x}\left(\lambda_{x} \frac{\partial T}{\partial x}\right)+\frac{\partial}{\partial y}\left(\lambda_{y} \frac{\partial T}{\partial y}\right)+\frac{\partial}{\partial z}\left(\lambda_{z} \frac{\partial T}{\partial z}\right)+\Phi
\end{gathered}
$$




$$
-\lambda_{\mathrm{m}}\left(\frac{\partial T}{\partial n}\right)=h\left(T_{\mathrm{w}}-T_{\mathrm{f}}\right)
$$

where $T_{\mathrm{gm}}$ and $T_{\mathrm{g}}$ are the average and transient gas temperatures, $\beta_{\mathrm{gm}}$ and $\beta_{\mathrm{g}}$ are the average and transient heat transfer coefficients, $\lambda_{x}, \lambda_{y}$, and $\lambda_{z}$ are the thermal conductivities of the material along $x, y$, and $z$ directions, respectively, $T$ is the temperature of the piston, $T_{\mathrm{w}}$ is the temperature of the piston surface, $T_{\mathrm{f}}$ is the flow temperature around the piston, $\lambda_{\mathrm{m}}$ is the thermal conductivity coefficient of the piston, $\varphi$ is the crank angle, $\tau$ is the time, and $\Phi$ is the internal heat source.

Fig. 9 presents the transient temperature and the heat transfer coefficient in the cylinder, and then the temperature and the heat transfer coefficient are averaged (by means of Eqs. (18) and (19)) and applied to the top surface of the piston mode. Piston thermal boundary conditions also consist of the ring groove, ring land, and skirt thermal boundary condition, underside thermal boundary condition, and piston pin bore boundary condition. These local thermal boundary conditions are determined by Yuan et al. (2005).

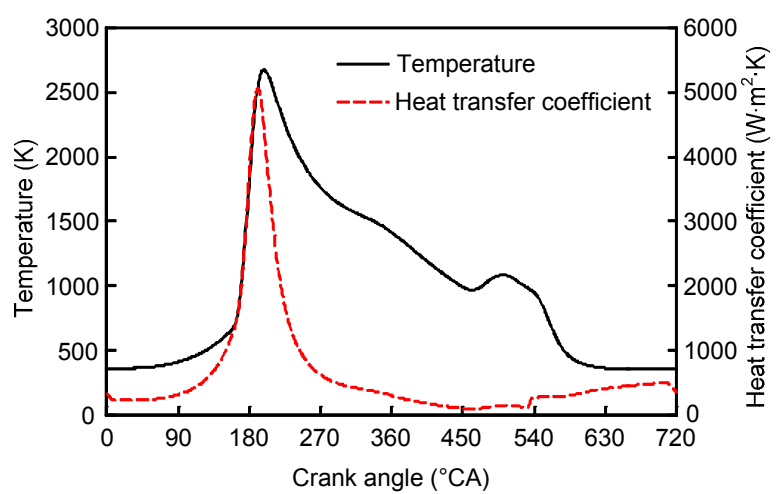

(a)
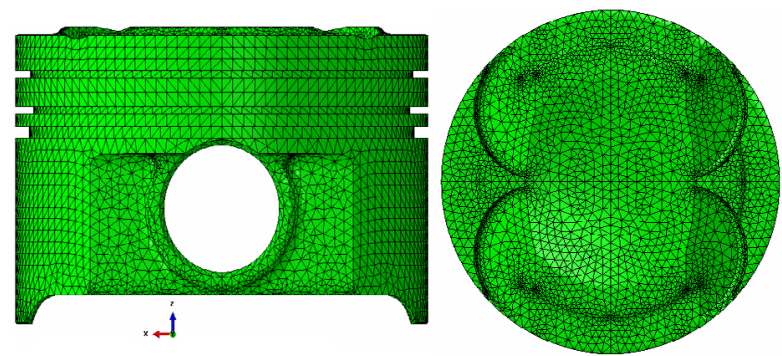

(b)

Fig. 9 Finite element model of piston and its thermal boundary condition of the top surface
(a) Temperature and heat transfer coefficient; (b) Finite ele- ment model of piston

The piston operates under high temperature in the cylinder. In addition to mechanical deformation, thermal deformation of the piston also has an effect on the pin bore deflection. Steady state thermal analysis and subsequent structural analysis are carried out to investigate the effect of thermal deformation on pin boss deflection. First, a 3D finite element thermal analysis is carried out to obtain its temperature distribution (Fig. 9b).

The temperature was measured on this piston with a temperature-plug technique (Fig. 10). The temperature measurement is employed to correct the thermal boundary conditions mentioned above.

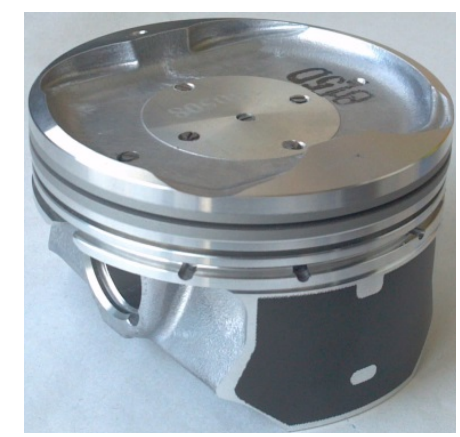

(a)

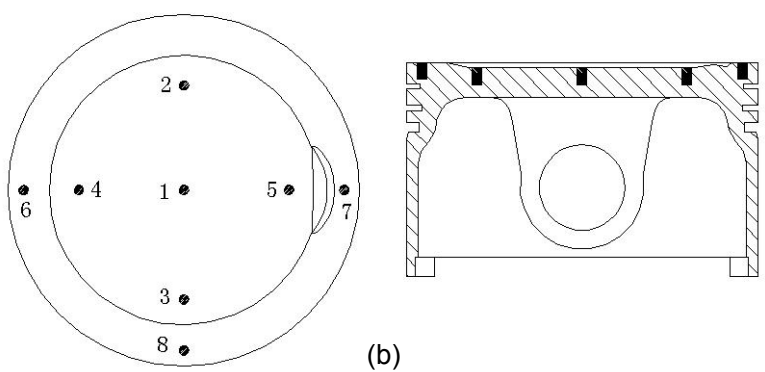

Fig. 10 Temperature measurement and test points (a) Experiment of the piston; (b) Position of measuring points

Fig. 11 presents the temperature contours of the piston simulated from finite element analysis. These results are verified by the experiment to modify the boundary condition, and then the more precise result will be gained. It can be seen that the temperature of the pin bore is in the range of $170-200{ }^{\circ} \mathrm{C}$. The maximum temperature appears at the top of the piston due to the high temperature adjacent to this surface.

The temperatures from measurement versus numerical simulations are listed in Table 5. The 
maximum error is about $6 \%$, which is acceptable for engineering analysis.

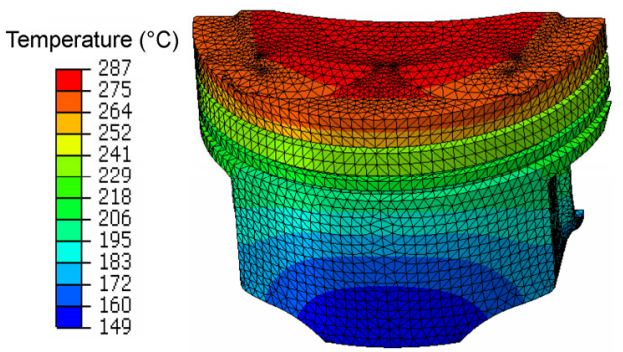

Fig. 11 Temperature field of the piston

Table 5 Measured temperature vs. simulated temperature

\begin{tabular}{cccc}
\hline \multirow{2}{*}{ Point } & \multicolumn{2}{c}{ Temperature $\left({ }^{\circ} \mathrm{C}\right)$} & \multirow{2}{*}{ Error $(\%)$} \\
\cline { 2 - 3 } & Measurement & Simulation & \\
\hline 1 & 270 & 283 & 5 \\
2 & 251 & 263 & 5 \\
3 & 257 & 263 & 2 \\
4 & 266 & 260 & 2 \\
5 & 246 & 260 & 6 \\
6 & 257 & 250 & 3 \\
7 & 241 & 250 & 4 \\
8 & 249 & 248 & 1 \\
\hline
\end{tabular}

\section{Results and discussion}

\subsection{Basic lubrication characteristics analyses}

Another crucial effect in pin bearing modeling is oil starvation or cavitation, since most pin bearings are supplied with splash oil normally. They have no oil supply from holes and grooves in the sliding direction. Pin bearings can only get oil in the axial direction through a suction effect which is caused by the sub-ambient pressure development when the two bearing surfaces separate. The oil flow is then balanced by the side leakage due to a squeezing effect. In this study, the cavitation region with the oil film is determined using a quasi-static cavitation algorithm. To validate the model, the lubrication characteristics, such as the minimum oil film thickness (MOFT), the maximum oil film thickness (MOFP), hydrodynamic friction power, and asperity friction power calculated with cavitation, are compared with the traditional model (Eq. (6)). The new equation governing cavitation is written as

$$
\begin{aligned}
& \frac{\partial}{\partial x}\left(\bar{\theta} \phi_{x} \frac{h^{3}}{\eta} \frac{\partial p}{\partial x}\right)+\frac{\partial}{\partial z}\left(\bar{\theta} \phi_{z} \frac{h^{3}}{\eta} \frac{\partial p}{\partial z}\right) \\
& =6\left(u_{1}+u_{2}\right) \frac{\partial}{\partial x}\left(\bar{\theta} h+\bar{\theta} \sigma \phi_{\mathrm{s}}\right)+12 \frac{\partial(\bar{\theta} h)}{\partial t},
\end{aligned}
$$

where $\bar{\theta}$ is the filling ratio.

Figs. $12 \mathrm{a}$ and $12 \mathrm{~b}$ present the MOFT and MOFP calculated with different models. The result shows that the trends of the MOFT and MOFP are nearly the same. However, the MOFT calculated with the traditional model is very different from the result of the cavitation model (Fig. 12a). The MOFT of cavitation model appears in one cycle at $384{ }^{\circ} \mathrm{CA}$, with its value of $0.63 \mu \mathrm{m}$, and the MOFT starts to appear at a small value at $82{ }^{\circ} \mathrm{CA}$ and ends at $636{ }^{\circ} \mathrm{CA}$ in the whole cycle. The MOFT of the traditional model in the whole cycle is $483{ }^{\circ} \mathrm{CA}$, which equals $0.74 \mu \mathrm{m}$. Fig. $12 \mathrm{~b}$ presents the MOFP of the pin boss calculated with different models. The result shows that the MOFP is nearly the same in the intake stage. However, the MOFP is larger in other strokes compared with the traditional model.

Figs. $12 \mathrm{c}$ and $12 \mathrm{~d}$ present the hydrodynamic friction power and the asperity friction power calculated with these different models. The results indicate that the maximum hydrodynamic friction power from the cavitation model is $31 \mathrm{~W}$, about $49 \mathrm{~W}$ less than that of the traditional model. They also occur at the crank angle of $375{ }^{\circ} \mathrm{CA}$. However, the maximum asperity friction power from the cavitation model is $380 \mathrm{~W}$ and the asperity contact starts from $80^{\circ} \mathrm{CA}$ and ends at $685^{\circ} \mathrm{CA}$. For the traditional model, the asperity friction power is $315 \mathrm{~W}$, the asperity contact starts from $330{ }^{\circ} \mathrm{CA}$ and ends at $645^{\circ} \mathrm{CA}$. It is also shown by Figs. $12 \mathrm{c}$ and $12 \mathrm{~d}$ that the hydrodynamic friction power from both models is much lower than the asperity friction power. The total friction power of the pin bore bearing is mainly determined by the asperity friction.

To find the reasons for the differences in the above and gain insight into the oil film distribution, the pressures at some typical crank angles are listed and compared. Fig. 13 presents the oil film pressure distribution at some typical crank angles, such as 30 , 375,420 , and $630{ }^{\circ} \mathrm{CA}$. When the crank angle is $30{ }^{\circ} \mathrm{CA}$, the pressure inclines to the bottom location at the snap ring side. Its maximum value is $5 \mathrm{MPa}$. With the piston moving toward the crank train, the pressure 

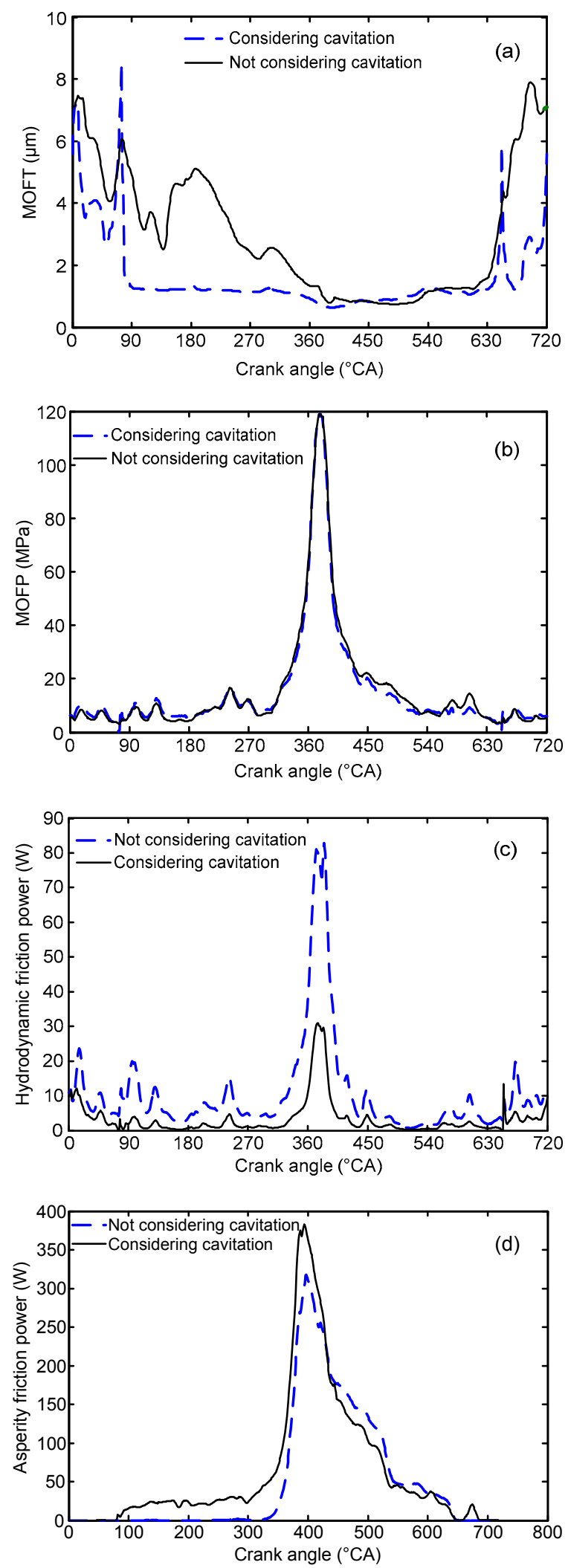

Fig. 12 Lubrication characteristics of the pin bore bearing (a) MOFT; (b) MOFP; (c) Hydrodynamic friction power; (d) Asperity friction power
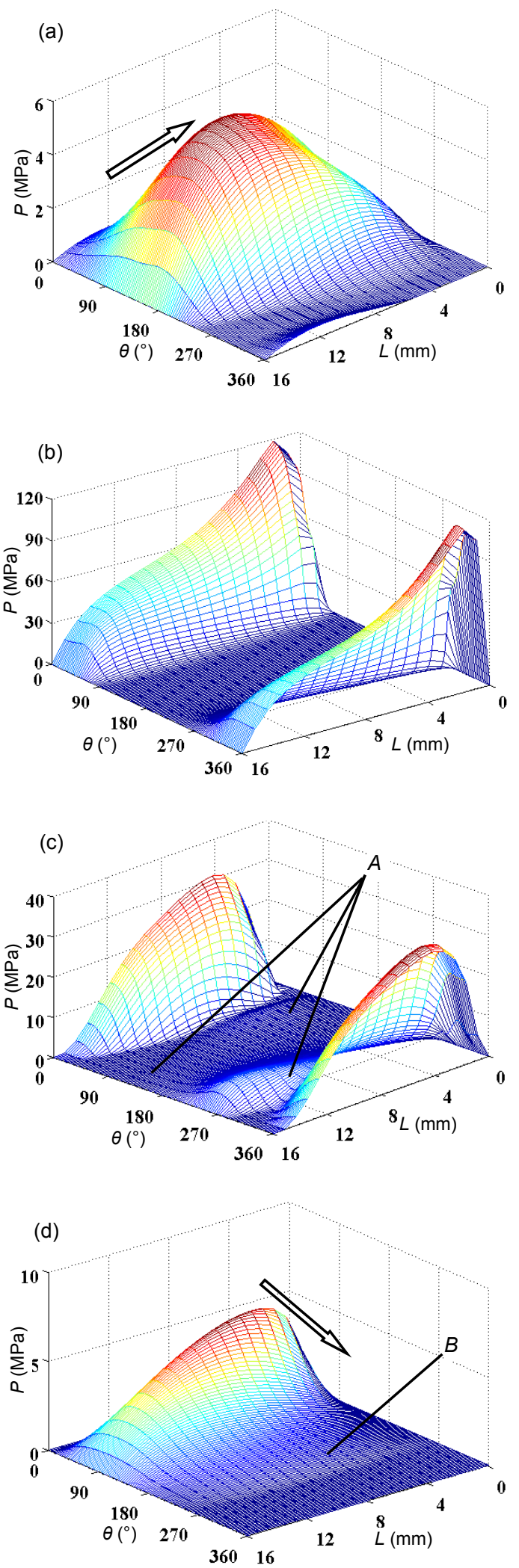

Fig. 13 Oil film pressure distribution at some typical crank angles (traditional model) ( $L$ is the bearing width) (a) $30{ }^{\circ} \mathrm{CA}$; (b) $375{ }^{\circ} \mathrm{CA}$; (c) $420{ }^{\circ} \mathrm{CA}$; (d) $630{ }^{\circ} \mathrm{CA}$ 
distribution will incline to another side of the pin bore bearing but still be at the bottom of the pin bore until $75^{\circ} \mathrm{CA}$ (as shown by the direction of the arrow in Fig. 13a, this phenomenon also needs to combine with Fig. $6 b$ to analyze the sum of the force, which decides the direction of the force). This is because of the deformation which is caused by the initial force. The piston is still moving along the crank train. However, the pressure will incline to the top side of the pin boss due to the deformation of the pin which is also caused by the changing direction of the inertial force. Fig. 13b presents the oil film distribution at the $375{ }^{\circ} \mathrm{CA}$. The result shows that with the pin deformed as shown in Fig. 7, it leads to the oil film pressure inclining to one side, and the main load supporting position locates at the top side of the bearing. Its maximum value is $116.9 \mathrm{MPa}$, which appears at the location of $350.9^{\circ}$. Fig. $13 \mathrm{c}$ presents the oil film distribution at $420^{\circ} \mathrm{CA}$. Its oil film distribution is similar to Fig. 13b. Its maximum value of the oil film is $31.7 \mathrm{MPa}$ which also locates at $350.9^{\circ}$, and position $A$ also supports the small load. When the crank angle is $630{ }^{\circ} \mathrm{CA}$, the oil film pressure starts to move to the region of $90^{\circ}-270^{\circ}$. Its maximum value is $5.4 \mathrm{MPa}$, which locates at $42.4^{\circ}$.

To investigate the reason for the difference from the traditional model, the pressure distributions calculated with the cavitation model at the $30,375,420$, and $630{ }^{\circ} \mathrm{CA}$ are also listed (Fig. 14). Fig. 14a presents the oil film pressure distribution at $30{ }^{\circ} \mathrm{CA}$, compared with the traditional model (Fig. 13a). The regions $C$ and $D$ do not compact the load due to the oil film rupture, and their maximum value is $6.5 \mathrm{MPa}$ which is larger than the traditional model. The reason is that a smaller region compacts the same load. The oil distribution at $375{ }^{\circ} \mathrm{CA}$ is nearly the same as the traditional model, but its maximum value is 118.4 MPa. Compared with the pressure distribution of the tradition model at $420{ }^{\circ} \mathrm{CA}$ and $630{ }^{\circ} \mathrm{CA}$ (as shown in $A$ and $B$ positions), positions $E$ and $F$ do not compact the load. Their maximum values are 28.3 and 5.5 MPa, and their positions are $354^{\circ}$ and $69.6^{\circ}$, respectively.

As is well known, the oil film can be partitioned into two zones: a cavitation zone and a full filling zone. An oil film will always rupture or reform in hydrodynamic lubrication. Fig. 15 presents the
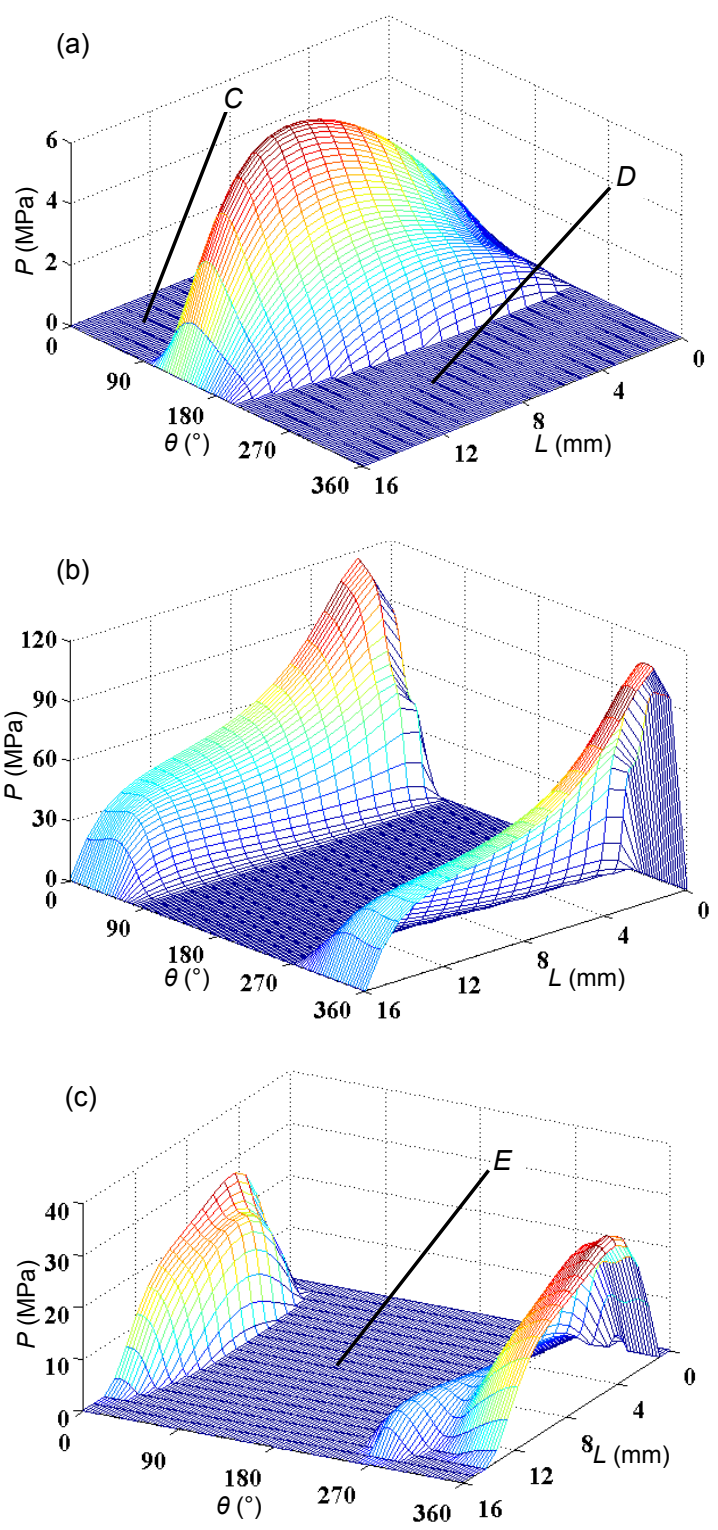

(d)

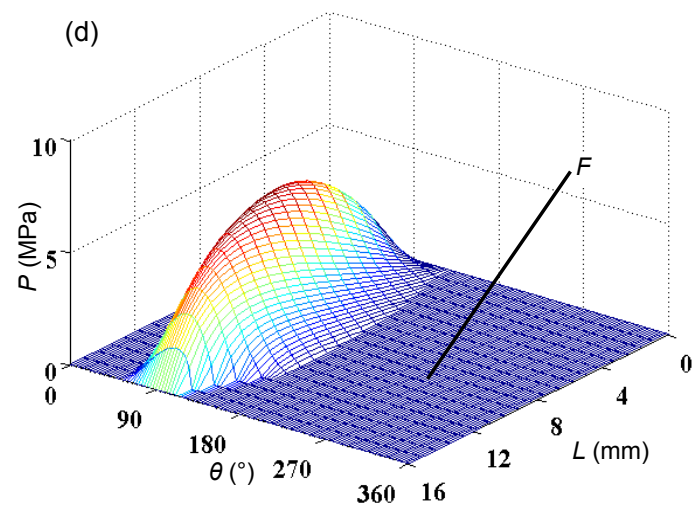

Fig. 14 Oil film pressure distribution at some typical crank angles (cavitation model)

(a) $30^{\circ} \mathrm{CA}$; (b) $375^{\circ} \mathrm{CA}$; (c) $420^{\circ} \mathrm{CA}$; (d) $630{ }^{\circ} \mathrm{CA}$ 

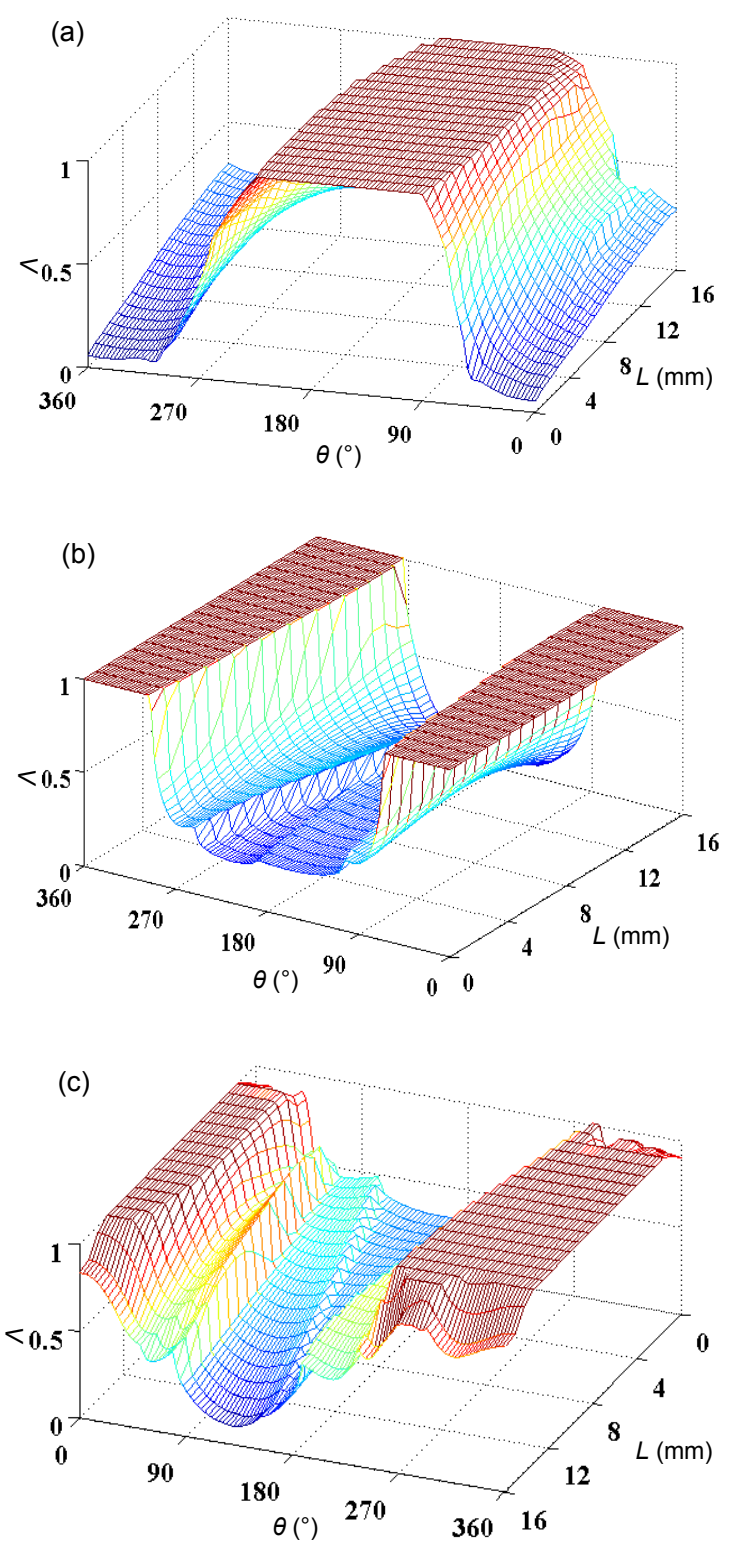

(d)

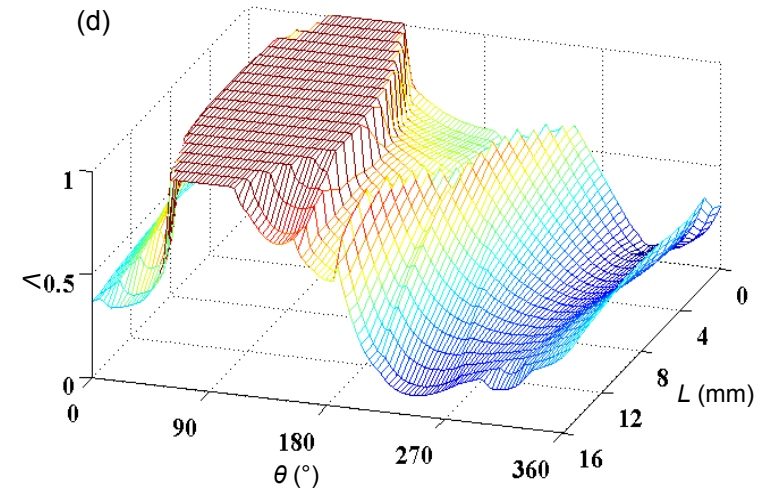

Fig. 15 Cavitation zone analysis at some typical crank angles

(a) $30{ }^{\circ} \mathrm{CA}$; (b) $375{ }^{\circ} \mathrm{CA}$; (c) $420{ }^{\circ} \mathrm{CA}$; (d) $630{ }^{\circ} \mathrm{CA}$ density of the oil film at some typical crank angles. Combined with the result of Fig. 14, the result shows that the region load compacting region is consistent with the oil film pressure compacting region. The density of these regions is equal to $\rho_{\mathrm{c}}$ (density ratio $\Lambda=\rho_{\mathrm{c}} / \rho$, where $\rho$ is the oil density) due to the oil film compressibility. The density locating at that region, which is less than $\rho_{\mathrm{c}}$, is the oil film cavitation zone due to the oil film rupturing.

\subsection{Effect of pin bore profile on lubrication}

To avoid asperity contact in the lubrication, the profile of the pin bore is usually designed to be one of square, parabola or flare. To investigate the effect of pin profile on the lubrication, lubrication performances calculated for these kinds of pin bore profile are compared (Fig. 16).

Fig. 17 presents the asperity friction power of the bearings with three different pin bore profiles. The results reveal that the highest asperity friction power occurs in the bearing with the trumpet pin bore, where

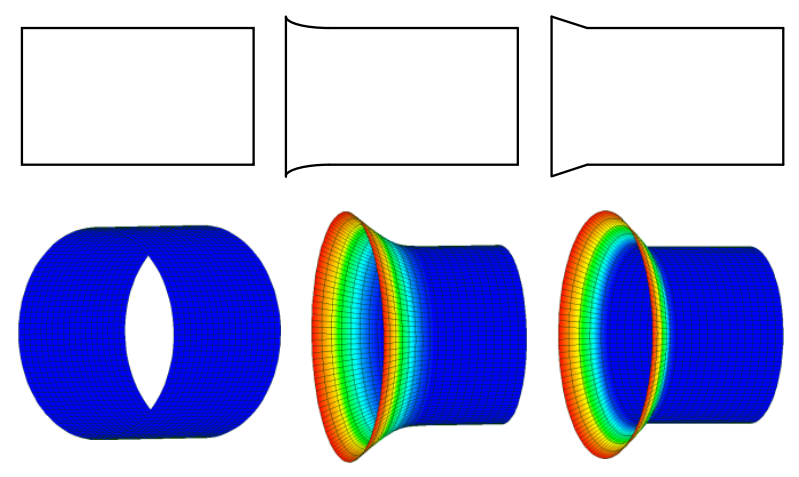

Fig. 16 Different pin bore profiles

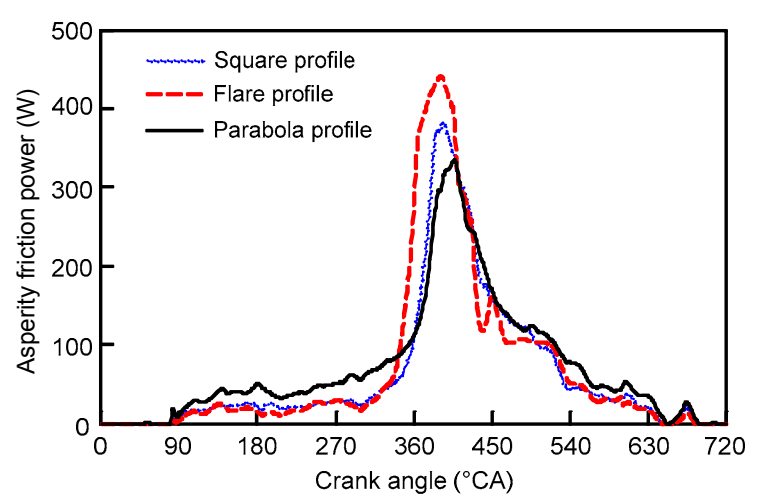

Fig. 17 Asperity friction power under different profiles of the pin bore bearing 
significant asperity contact appears at the transition between the straight part and tapered part of the pin bore. The pin bore with the parabola profile produces the lowest asperity friction power because in this case the contact pressure between the pin and the pin bore distributes more evenly.

Fig. 18 presents the oil film pressure distribution and asperity contact pressure distribution at $380{ }^{\circ} \mathrm{CA}$. When the profile is square, the oil film pressure clearly inclines to one side due to the deformation of the pin which leads to a small clearance of this side of the pin bore and journal misalignment. It also leads to the maximum oil film pressure in this region, which is $347.9^{\circ}$ along the circumferential direction and $1.684 \mathrm{~mm}$ along the width, and its value is $118.2 \mathrm{MPa}$. At $p_{L=0}=0$, the oil will collapse near the edge. The misalignment of the journal also leads to asperity contact at the edge of the pin bore bearing. Its location is $24.2^{\circ}$ along the circumference, and the maximum asperity contact pressure is $61.2 \mathrm{MPa}$. The misalignment also leads to the maximum asperity contact pressure and the maximum oil film pressure appears

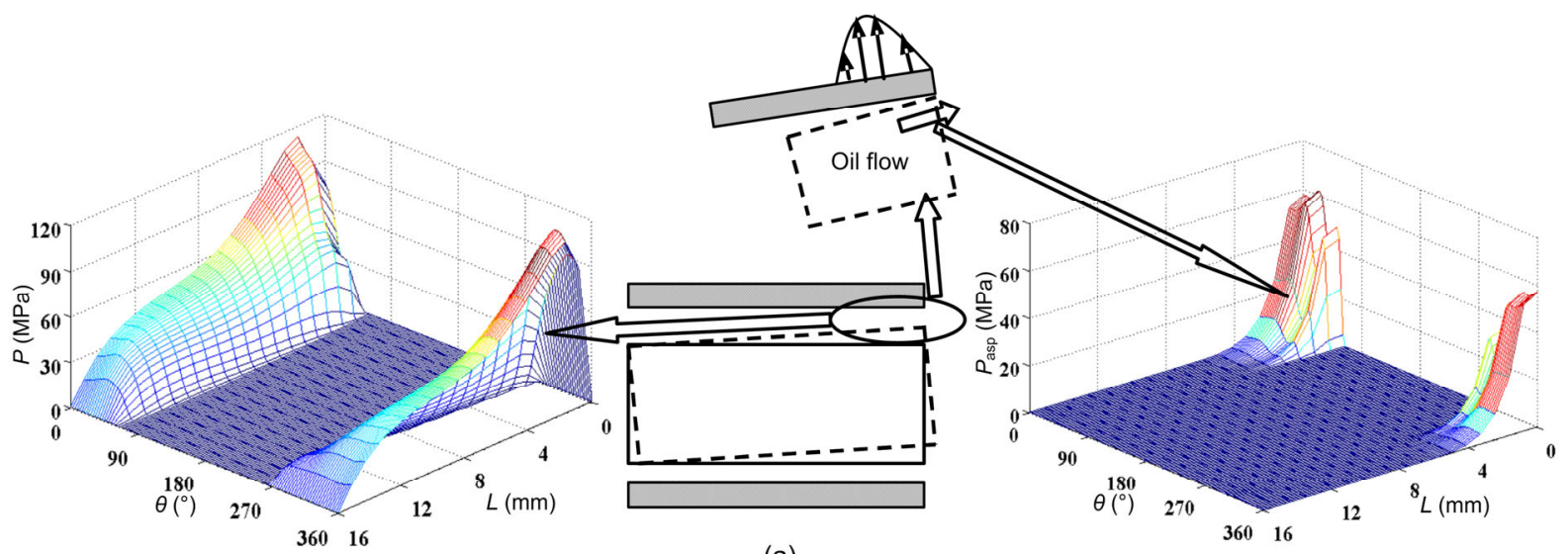

(a)

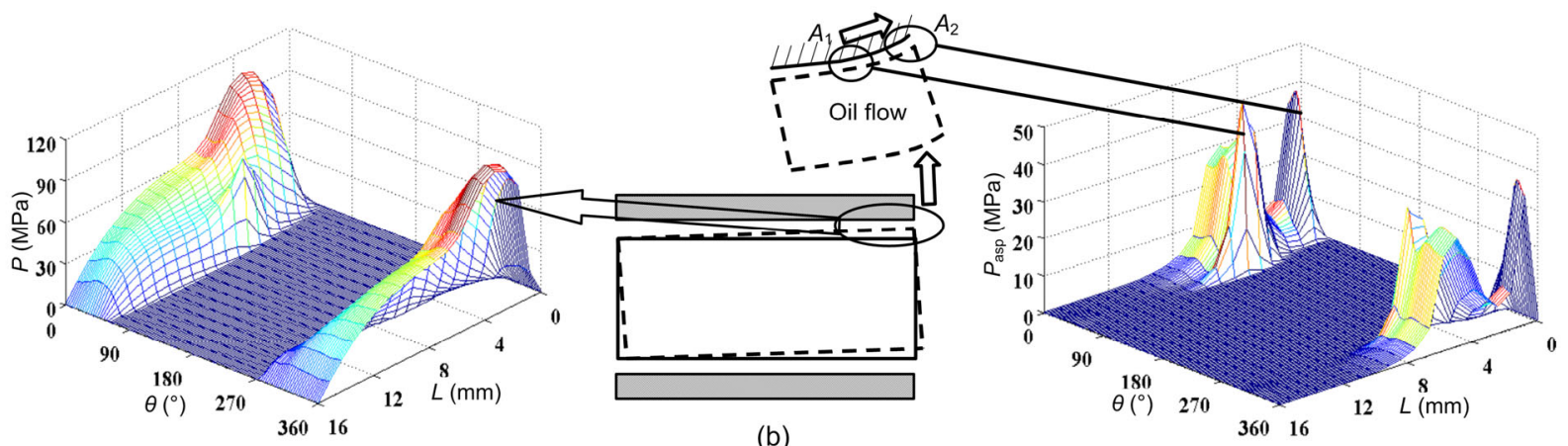

(b)

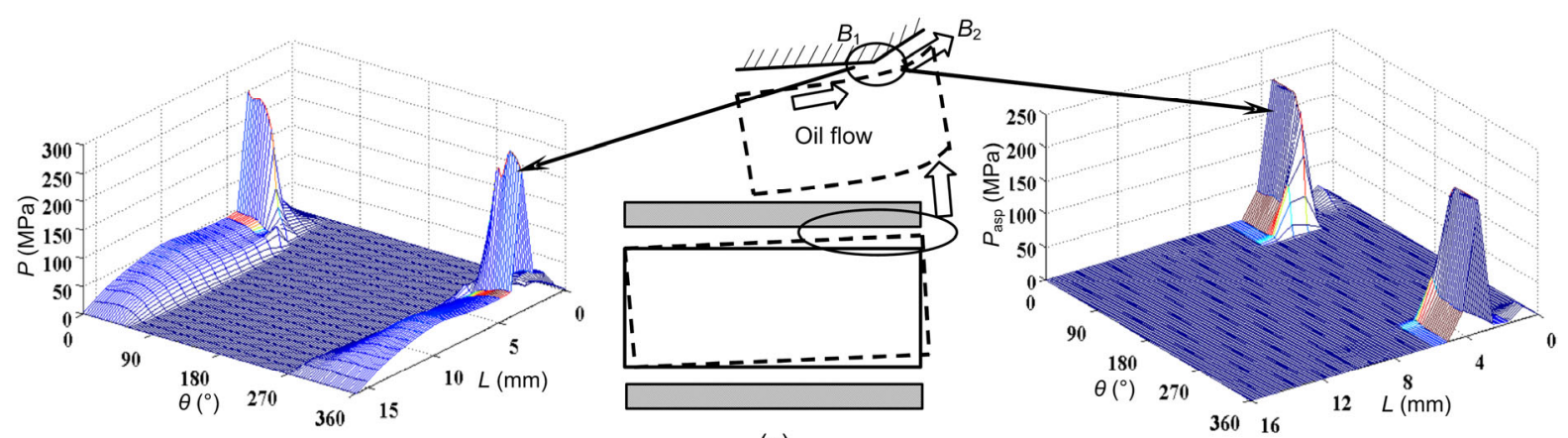

(c)

Fig. 18 Oil film pressure and asperity contact pressure distribution under journal misalignment (a) Square profile; (b) Parabola profile; (c) Flare profile 
at different positions. When the profile of the pin bore is parabolic, the maximum oil film pressure appears at $3.4 \mathrm{~mm}, 350.9^{\circ}$, and its maximum value is $106 \mathrm{MPa}$. However, the asperity contact is different with the square profile. Here, two peak values appear at $0.8 \mathrm{~mm}$ and $5.9 \mathrm{~mm}$, and the values are $38.9 \mathrm{MPa}$ and $46.0 \mathrm{MPa}$, respectively. The asperity contact pressure is clearly smaller compared with the above results. The reason is that the clearance is smaller at the transition of the profile (shown as $A_{1}$ position in Fig. 18b) due to deformation of the pin. That is why the asperity contact also appears at this position, and it is good for the formation of the hydrodynamic lubrication for suitable of clearance changing in the case of the parabolic profile (shown as $A_{2}$ position in Fig. 18b). However, there is another peak asperity contact pressure because of large pin deformation which is larger than the pin bore deflection. Fig. 18c presents the oil film pressure distribution and asperity contact pressure distribution at $380^{\circ} \mathrm{CA}$ when the profile is flare. The result shows that peak oil film pressure is $278.6 \mathrm{MPa}$, at $3.4 \mathrm{~mm}$ along the width. The peak asperity contact pressure is $200 \mathrm{MPa}$ which is also at $3.4 \mathrm{~mm}$ along the width, and the wear concentrates in a small place. The reason for this phenomenon is that when the pin bore profile is flare, the clearance at position $B_{1}$ is smaller than any other place (Fig. 18c), which is also why the peak oil film pressure and peak asperity contact pressure occur here. The hydrodynamic lubrication is weak due to the higher gradient of the clearance, and the asperity contact also appears at the region $B_{2}$. In fact, when the oil film pressure and asperity contact disappear, the moment produced by these forces also disappears, which will intensify the wear of the bearing.

Because of the difficulty in establishing an experiment on the piston pin, we verified our results from wear patterns and the wear region. The real engine experiment for the piston pin joint was carried out, and when we found the wear problem, we did the simulation and found good agreement with the wear patterns (as shown in regions $A$ and $B$ in Fig. 19).

\subsection{Effect of pin stiffness on the lubrication}

There are different options in ways to study the effect of pin stiffness on the lubrication: (1) changing the material of the piston pin, and (2) changing the

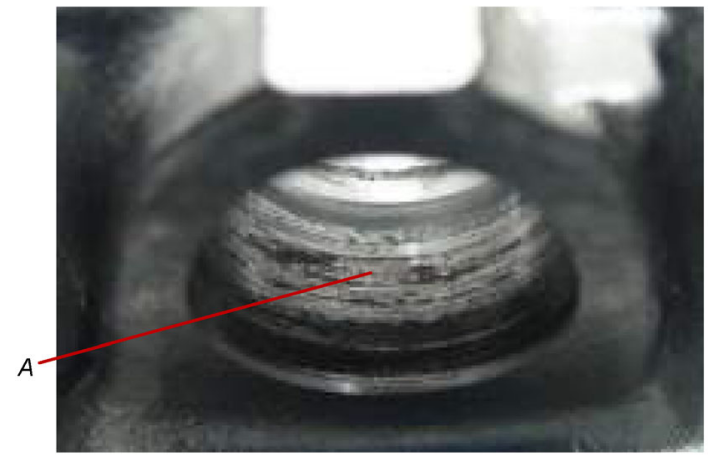

(a)

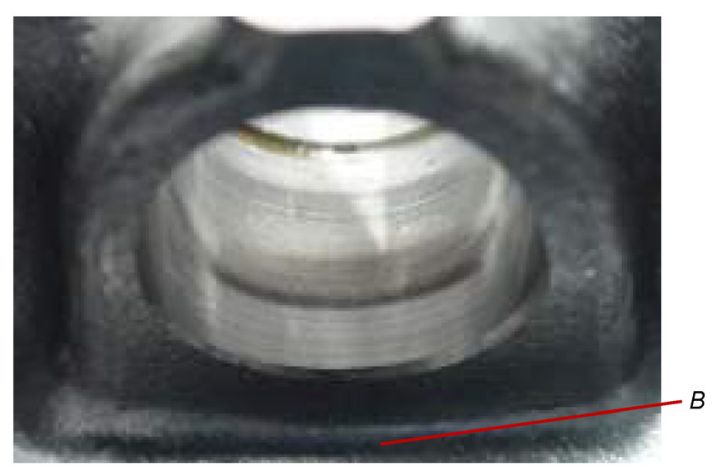

(b)

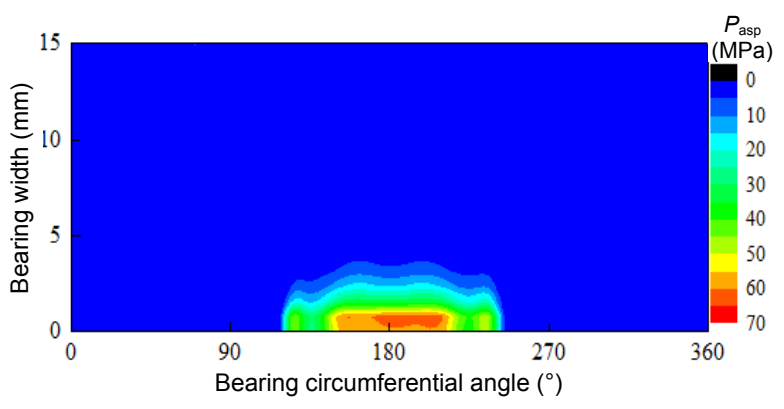

(c)

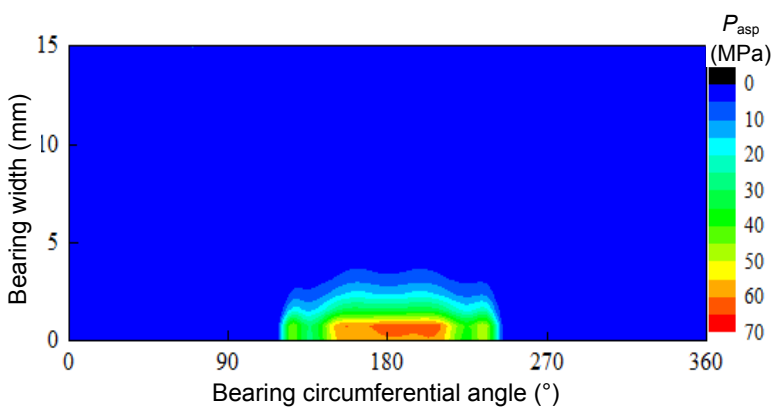

(d)

Fig. 19 Verification for the wear patterns of the pin bore in engine hot scuff test: wear patterns for the square (a) and parabolic (b) pin bore profiles; asperity contact pressure distribution for parabolic (c) and cylindrical square (d) pin bore profiles 
diameter of the hollow part. In this study, the pin is designed to three modes with three different hollow diameters. Fig. 20 presents the solid model and finite element models with different hollow diameters.

Fig. 21 presents the friction power of the bearings with different pin inner diameters. It reveals that higher asperity friction power appears in the pin bearing with smaller pin inner diameter, especially during the power stroke. However, the value of the four curves shows little difference during the other three strokes due to the fact that significant pin deflection mainly occurs during the power stroke.

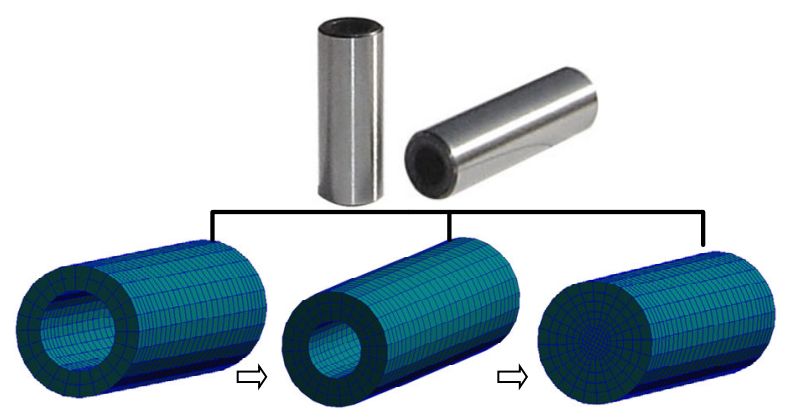

Fig. 20 Different pin structures with different stiffness

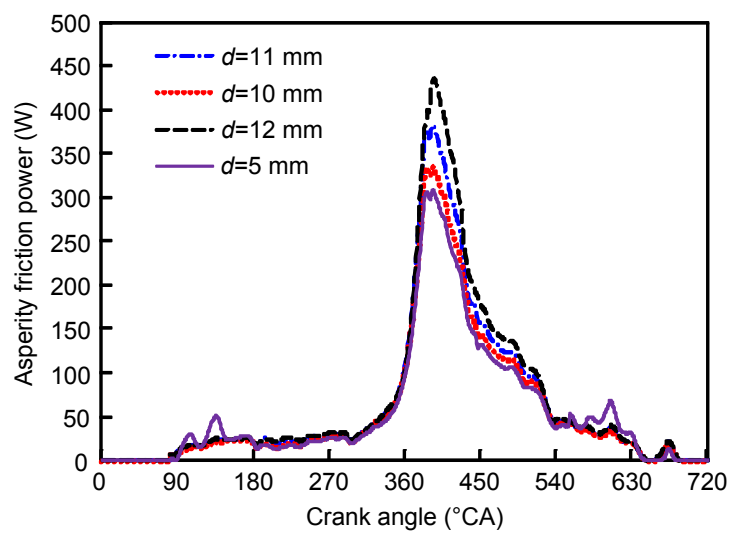

Fig. 21 Asperity friction power under different hollow diameters of the pin

Fig. 22 presents the oil film pressure distribution under different hollow diameters. When the hollow diameter is $12 \mathrm{~mm}$, the stiffness is smaller than $d=11 \mathrm{~mm}$. The deflection at the same position is clearly larger (Fig. 22a).

The maximum oil film pressure is $123.8 \mathrm{MPa}$, which appears at $\left(1.7 \mathrm{~mm}, 347.9^{\circ}\right)$, the asperity con- tact pressure appears at $\left(0,24.2^{\circ}\right)$, and its maximum value is $70.47 \mathrm{MPa}$. It is clearly larger than $61.2 \mathrm{MPa}$ in the above, so too large a hollow diameter will increase the wear of the bearing. When $d=10 \mathrm{~mm}$, the deflection will be smaller. The maximum oil film pressure is $113.7 \mathrm{MPa}$, which appears at $(1.684 \mathrm{~mm}$, $\left.347.9^{\circ}\right)$, the asperity contact pressure appears at $\left(0,24.2^{\circ}\right)$. Its maximum value is $55.3 \mathrm{MPa}$. Another stiffness model with pin $d=5 \mathrm{~mm}$ is also compared with the above model. The result shows that the maximum oil film pressure is $101.8 \mathrm{MPa}$, which appears at $\left(4.2 \mathrm{~mm}, 350.9^{\circ}\right)$. The asperity contact pressure appears at $\left(5.895 \mathrm{~mm}, 51.4^{\circ}\right)$. Its maximum value is $45.7 \mathrm{MPa}$. However, an interesting phenomenon happens. A peak asperity contact appears at the edge of the bearing when $d=5 \mathrm{~mm}$. In a realistic design of the pin, to avoid high initial force of the piston system and meet the demand for reliability of the pin, reducing the mass of the pin and reliability is a trade-off problem, so a suitable design of the hollow diameter is very important.

\subsection{Effect of thermal deformation on lubrication and dynamic characteristics}

To obtain the deformation matrix of the pin bore, a structural analysis is carried out to obtain the thermal deformation by applying the temperature distribution from the piston thermal analysis. Its deformation is added to the lubrication problem by adding the pin bore profile to the oil film thickness. The thermal deformation of the pin bore is shown in Fig. 23, where the deformations are scaled 200 times.

Fig. 24 presents the profile of the pin bore which adds the radical deformation to the structure. The result shows that the top surface of the piston crown wall is exposed to a higher temperature than the bottom surface. Therefore, greater thermal expansion at the top surface results in the piston crown wall bending towards the underside, which subsequently triggers the deflection of the pin boss towards the inner side. The real angular misalignment is $0.073^{\circ}$ in thermal deformation. It can be expected that the effect of thermal deformation on the pin boss bearing is as significant as that of mechanical deformation.

Fig. 25 (p.460) presents the asperity friction power of the bearings with and without considering thermal deflection of the pin bore. The maximum 


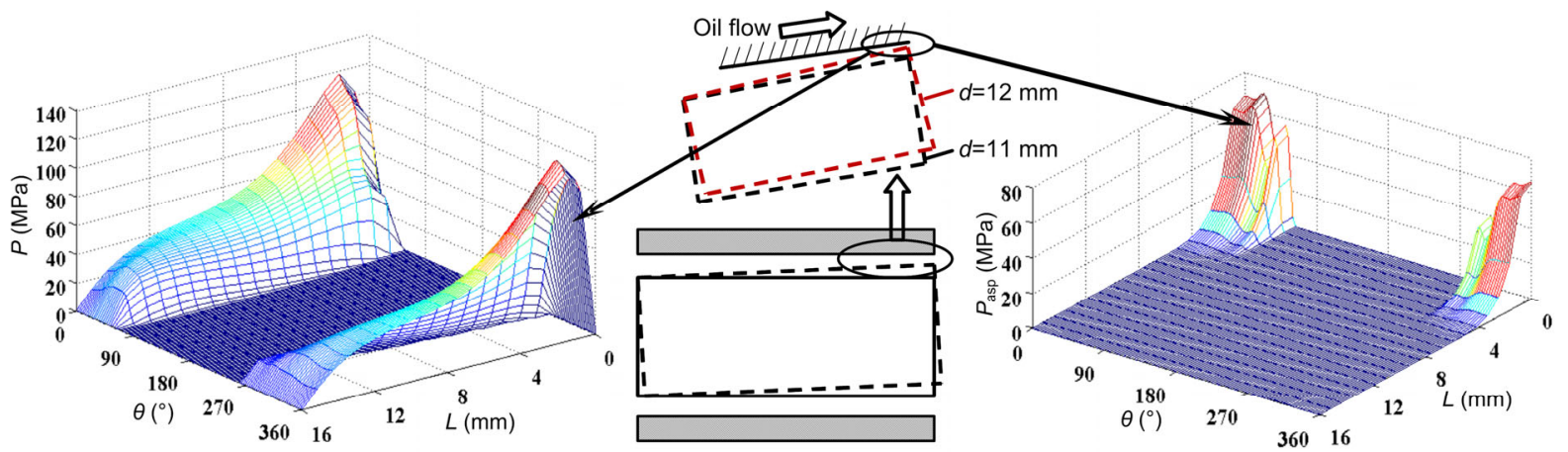

(a)

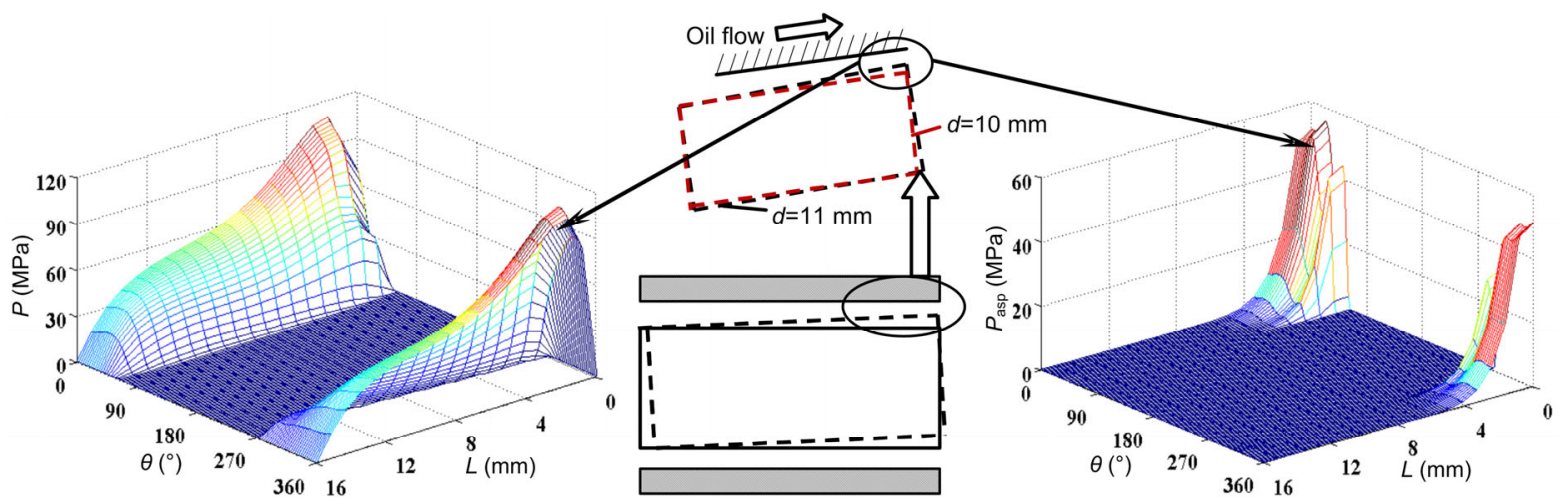

(b)

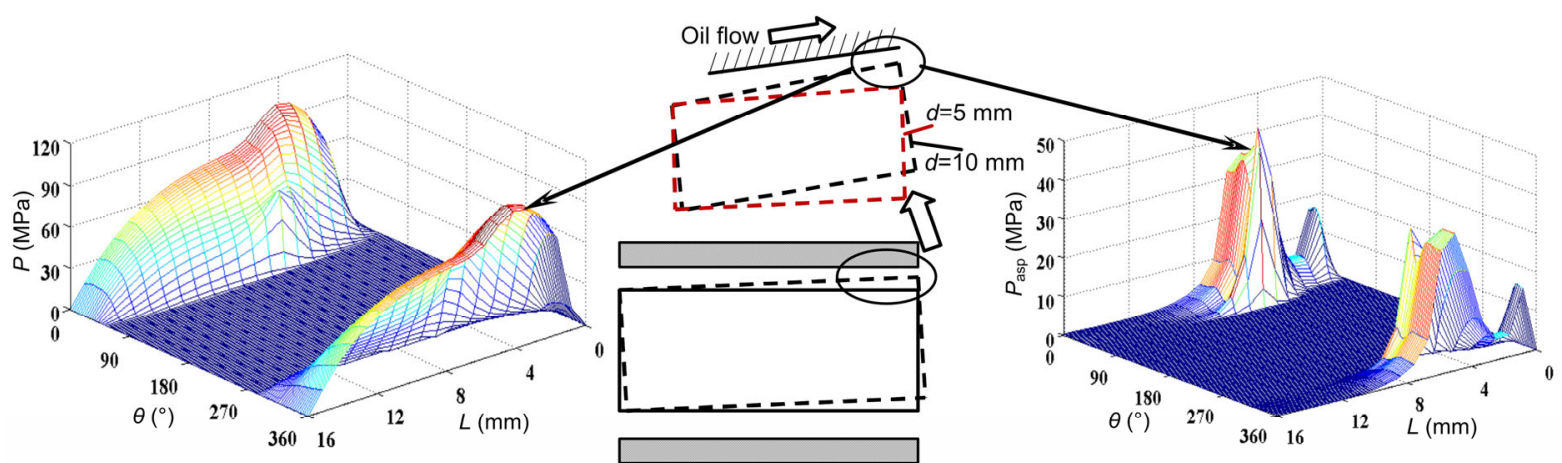

(c)

Fig. 22 Distribution of pressure and asperity contact pressure with different hole diameters: (a) $d=12$ and $11 \mathrm{~mm}$, (b) $d=10$ and $11 \mathrm{~mm}$, and (c) $d=5$ and $10 \mathrm{~mm}$

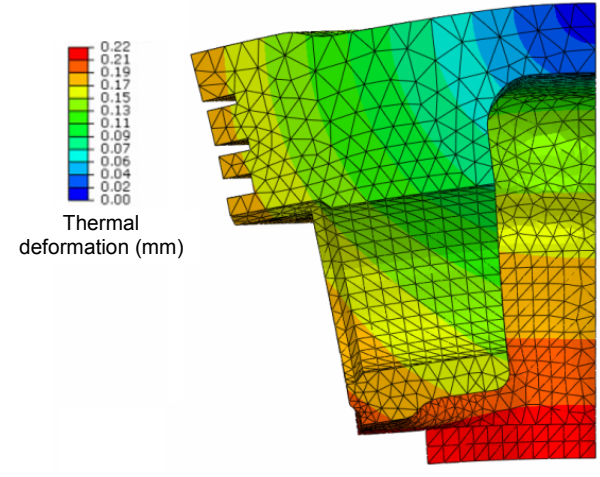

Fig. 23 Pin bore thermal deformation (scaled 200 times)

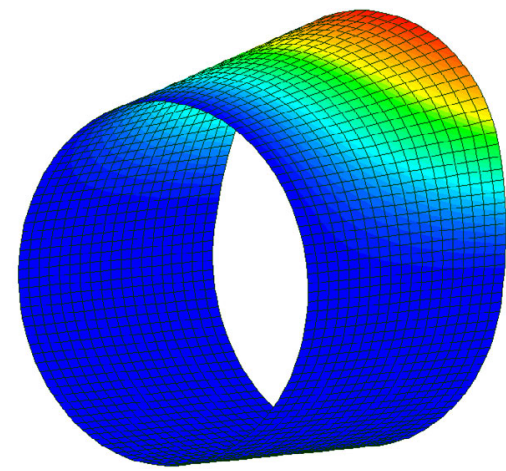

Fig. 24 Pin boss profile considering thermal deformation 
asperity friction power (occurring around TDC) is lower when considering the thermal deflection, because the pin bending deflection under the gas load agrees with the pin bore thermal deflection. So the concentrated contact pressure (occurring around TDC) at the inner edge of the pin bore decreases.

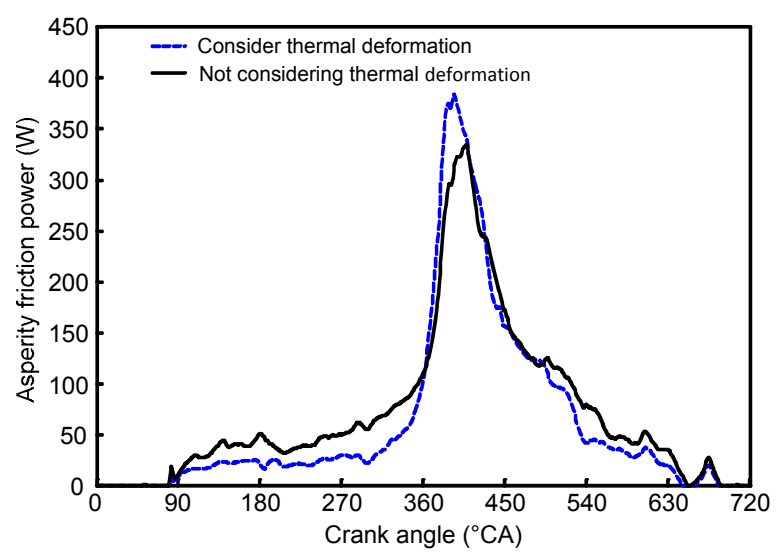

Fig. 25 Effect of thermal deformation on asperity friction power
Fig. 26 presents the distribution of pressure and asperity contact pressure considering thermal deformation. The result shows that when the thermal deformation is considered, the maximum value is $122.5 \mathrm{MPa}$, and it appears at $\left(1.7 \mathrm{~mm}, 347.9^{\circ}\right)$. The maximum value of asperity contact pressure is 118.1 $\mathrm{MPa}$, which appears at $\left(0,18.2^{\circ}\right)$, where one section $m=5, n=1: 20$ (Fig. 26b) ( $m$ is the mesh number of the finite element along circumferential direction, and $n$ is the mesh number along the width). The result shows that the pressure $p_{L=0-8}$ is larger and the pressure $p_{L=9-16}$ is smaller when the thermal deformation is considered. The reason is that when the thermal deformation is considered, all the profile will incline to the top side of the piston. However, the deformation of the other side of the pin hole is smaller. To fit in the circle of the pin hole, the dynamic motion of the pin is changed, the misalignment increases through the analysis of orbit, which intensifies the wear at the edge of the bearing, so it is very important to consider the effect of thermal deformation on the lubrication.

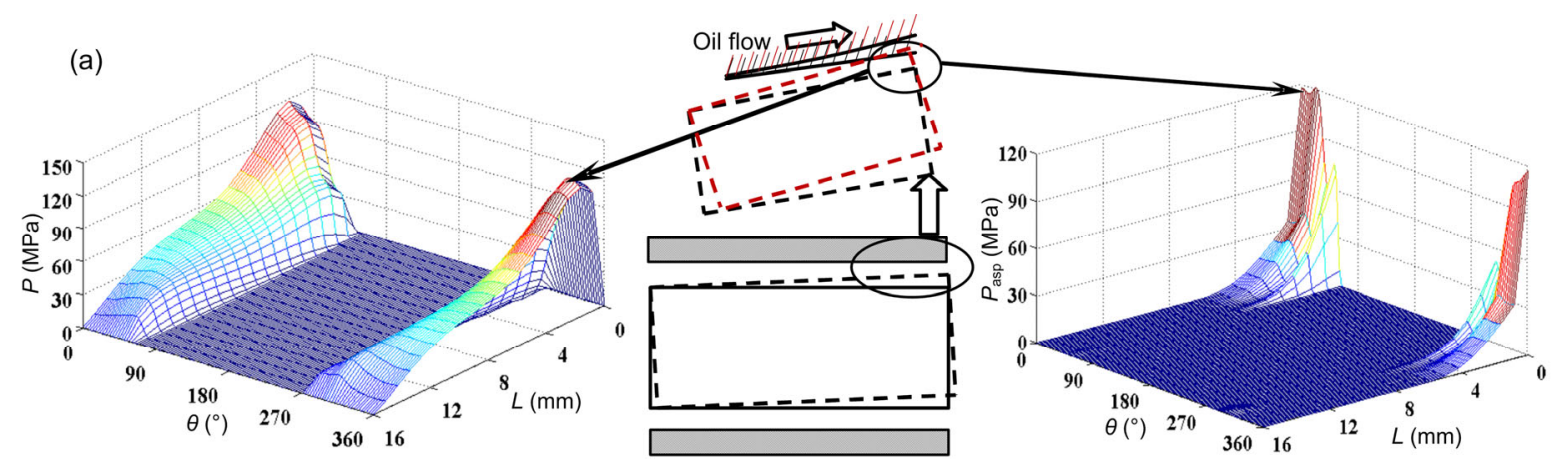

(b)

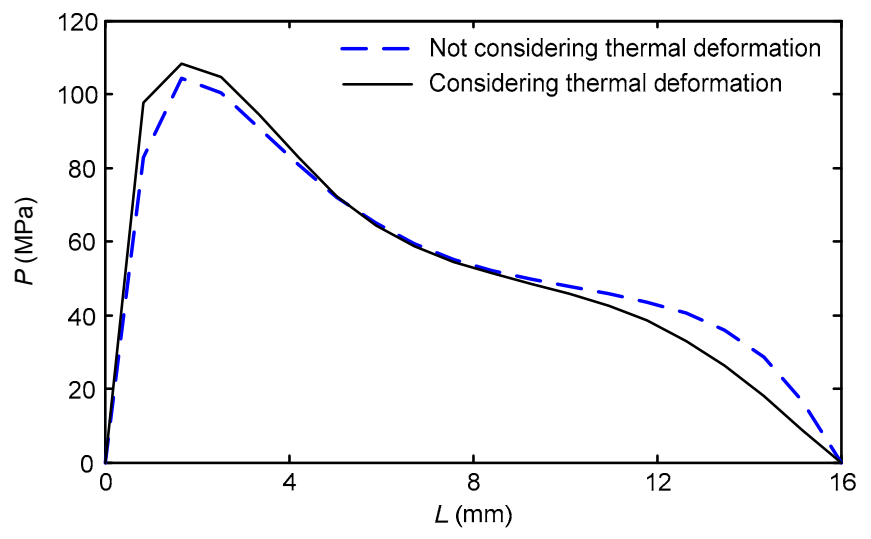

Fig. 26 Distribution of pressure and asperity contact pressure considering thermal deformation (a) Distribution of pressure and asperity contact pressure at $380{ }^{\circ} \mathrm{CA}$; (b) Oil film comparison at one section 


\section{Conclusions}

A multi-body dynamic model is built to analyze the lubrication of the piston pin. Some results are compared with different lubrication models and pin structures. Findings are obtained by comparing various models. Conclusions can be summarized as follows:

1. A multi-body dynamic model for the piston system based on component mode synthesis method is established. The elastic deformation and cavitation are considered in the model. To solve the mismatch of coarse finite element mesh and fine finite difference mesh, a 2D interpolation method is introduced to the model, and then a coarse FEM mesh density can be used for bearing structure to reduce the amount of computation. Fine finite difference mesh helps to solve the problem of sharp gradients resulting from the eccentric position of the piston pin.

2. The lubrication analysis of the piston pin combined with the deformation of the pin is implemented. When the peak cylinder pressure acts on the top surface of the piston crown, and the connecting rod supports the pin, this causes the pin to be misaligned. This is why the asperity contact occurs at the inside of the pin bore.

3. Comparing all the pressure results calculated with the traditional model, the result shows that the trends of the MOFT and MOFP are nearly the same. However, the MOFT calculated with the traditional model is obviously different from that using the cavitation model. They appear at different crank angles for the two different models, i.e., $483{ }^{\circ} \mathrm{CA}$ and $384^{\circ} \mathrm{CA}$, respectively. The pressure distributions at some typical crank angles are compared. What causes the MOFP to be different is that some regions do not compact the load due to the oil film rupture. The pressure compacting region is consistent with the density due to the oil film compressibility.

4. The oil film pressure and asperity contact pressure at peak cylinder pressure are compared for three different bin bore profiles: square profile, parabola profile, and flare profile. Parabolic profile can reduce the wear to some extent. However, flare pro- file intensifies the wear of some places, but reduces the regions. The reasons for these differences are explained. All the results can provide guidance for the design of the pin bore.

5. To investigate the effect of the stiffness of the pin on the lubrication, lubrication performances of pins with different inner diameters are compared. The result agrees well with elastic theory. However, in a realistic design of the pin, to avoid high inertial force of the piston system and meet the demand for reliability of the pin, reducing the mass of the pin and reliability is a trade-off problem, so a suitable design of the hollow diameter is very important. The thermal deformation is also added to the model. It intensifies the wear at the edge of the bearing, so it is very important to consider the thermal deformation to the lubrication.

\section{References}

Andersson, B.S., 1991. Company's perspective in vehicle tribology. Proceeding of the 18th Leeds-Lyon Symposium, Lyon, France, p.3-6.

Baker, C.E., Theodossiades, S., Rahnejat, H., et al., 2012. Influence of in-plane dynamics of thin compression rings on friction in internal combustion engines. Journal of Engineering for Gas Turbines and Power, 134(9): 092801. [doi:10.1115/1.4006690]

Clark, K., Antonevich, J., Kemppainen, D., et al., 2009. Piston pin dynamics and temperature in a CI Engine. SAE International Journal of Engines, 2(1):91-105. [doi:10. 4271/2009-01-0189]

Craig, R.R.Jr., Bampton, M.C.C., 1968. Coupling of substructures for dynamic analyses. AIAA Journal, 6(7): 1313-1319. [doi:10.2514/3.4741]

Etsion, I., Halperin, G., Becker, E., 2006. The effect of various surface treatments on piston pin scuffing resistance. Wear, 261(7-8):785-791. [doi:10.1016/j.wear.2006.01. 032]

Fridman, V., Piraner, I., Clark, K., 2006. Modeling of mixed lubrication conditions in a heavy duty piston pin joint. ASME Internal Combustion Engine Division Spring Technical Conference. Aachen, Germany, p.741-748. [doi:10.1115/ICES2006-1412]

Greenwood, J.A., Williamson, J.B.P., 1966. Contact of nominally flat surfaces. Proceedings of the Royal Society A: Mathematical, Physical and Engineering Sciences, 295(1442):300-319. [doi:10.1098/rspa.1966.0242]

He, Z.P., Zhang, J.H., Li, Z.Y., et al., 2013. Inter-asperity cavitation for misalignment journal lubrication problem based on mass-conservative algorithm. Journal of 
Zhejiang University-SCIENCE A (Applied Physics \& Engineering), 14(9):642-656. [doi:10.1631/jzus. A1300080]

Ligier, J.L., Ragot, P., 2005. Piston pin: wear and rotating motion. SAE Technical Paper No. 2005-01-1651. [doi:10. 4271/2005-01-1651]

Littlefair, B., de la Cruz, M., Theodossiades, S., et al., 2014. Transient tribo-dynamics of thermo-elastic compliant high-performance piston skirts. Tribology Letters, 53(1): 51-70. [doi:10.1007/s11249-013-0243-6]

Nishikawa, C., 2012. Optimization of semi-floating piston pin boss formed by using oil-film simulations. SAE Technical Paper No. 2012-01-0908. [doi:10.4271/201201-0908]

Patir, N., Cheng, H.S., 1978. An average flow model for determining effects of three-dimensional roughness on partial hydrodynamic lubrication. Journal of Tribology, 100(1):12-17. [doi:10.1115/1.3453103]

Richardson, D.E., 2000. Review of power cylinder friction for diesel engines. Journal of Engineering for Gas Turbines and Power, 122(4):506-519. [doi:10.1115/1. 1290592]

Robinson, J.E., 1965. Piston-boss and wrist-pin design. Journal of Engineering for Gas Turbines and Power, 87(4): 412-420. [doi:10.1115/1.3678290]

Shi, F., 2011. An analysis of floating piston pin. SAE International Journal of Engines, 4(1):2100-2105. [doi:10.4271/ 2011-01-1407]

Suhara, T., Ato, S., Takiguchi, M., et al., 1997. Friction and lubrication characteristics of piston pin boss bearings of an automotive engine. SAE Technical Paper No. 970840. [doi:10.4271/970840]

Takeuchi, A., 2011. Investigation on lubrication condition of piston pin in real engine block with ultrasonic technique. Lubrication Science, 23(7):331-346. [doi:10.1002/1s. 159]

Takiguchi, M., Nagasawa, K., Suhara, T., 1996. Friction and lubrication characteristics of small end connecting rod bearing of an automotive engine. 18th Annual Fall Technical Conference of the ASME Internal Combustion Engine Division, Part 2, Fairborn, USA, p.1-6.

Wang, X., Du, J., Zhang, J., 2011. Mixed lubrication analysis of piston pin bearing in diesel engine with high power density. ASME/STLE International Joint Tribology Conference. American Society of Mechanical Engineers, p.167-169. [doi:10.1115/IJTC2011-61185]

Xu, H.J., 2005. Predictive Modeling of Piston Assembly Lubrication in Reciprocating Internal Combustion Engines. PhD Thesis, The University of Texas at Austin, America.

Yuan, Y.P., Zhang, W.Z., Cheng, X.G., et al., 2005. Study of piston's transient temperature-field distributing orderliness for heavy duty engines. Chinese Internal Combus- tion Engine Engineering, 26(4):35-38 (in Chinese).

Zhang, C., Cheng, H.S., Qiu, L., et al., 2003. Scuffing behavior of piston-pin/bore bearing in mixed lubrication-Part I: experimental studies. Tribology transactions, 46(2):193199. [doi:10.1080/10402000308982616]

Zhang, C., Cheng, H.S., Wang, Q.J., 2004. Scuffing behavior of piston-pin/bore bearing in mixed lubrication-Part II: scuffing mechanism and failure criterion. Tribology transactions, 47(1):149-156. [doi:10.1080/0569819049 0279100]

\section{中文概要}

\section{题 目: 考虑活塞-活塞销系统结构变形及空穴机理的活 塞销润滑分析}

目 的: 建立柔性结构下的活塞-活塞销耦合系统的润滑模 型, 分析活塞销的形貌和结构对活塞销的摩擦磨 损的影响, 为活塞销的设计提供参考依据。

创新点: 1. 建立柔性结构下的活塞销多体动力学模型, 将 空穴理论与活塞销润滑模型耦合, 研究活塞销的 润滑情况; 2. 考虑活塞的热变形, 使得活塞销润 滑情况更贴近于实际; 3. 将活塞销的干接触位置 与实际活塞销磨损位置进行对比, 验证活塞销的 易磨损部位。

方 法: 1. 基于有限元理论构建活塞-活塞销耦合系统润滑 分析所需的有限元模型 (图 3); 2. 基于模态缩减 理论建立活塞-活塞销耦合系统多体动力学仿真 模型, 将热变形耦合于活塞销型线中（图 4); 3. 分析活塞销的基本润滑特性, 比较空穴现象对 润滑的影响 (图 12-15); 4. 分析不同型面的活塞 销的润滑特性, 比较各种型线下活塞销的润滑情 况 (图 16-18); 5. 分析不同销孔内径下活塞销的 润滑特性 (图 21 和 22)。

结 论: 1. 在活塞销润滑问题分析中, 考虑到有限差分网 格密度和有限元网格密度不一致, 采用节点插值 算法解决压力不收敛问题; 2. 从压力作用于活塞 顶部的形式方面分析, 研究活塞销易发生干接触 的部位; 3. 对比分析是否考虑空穴机理的活塞销 润滑特性; 研究结果表明, 由于油膜破裂导致油 膜不能承受载荷, 且承受油膜压力位置的密度为 油膜密度, 其它区域小于油膜密度; 4. 对比不同 型线下活塞销的干接触情况, 为活塞销的设计提 供参考依据; 5. 研究不同活塞销孔内径下的润 滑, 考虑活塞销的热变形, 使得润滑分析更贴近 实际。

关键词: 活塞销; 活塞销座; 轴承; 润滑; 空穴 


\section{Appendix A}
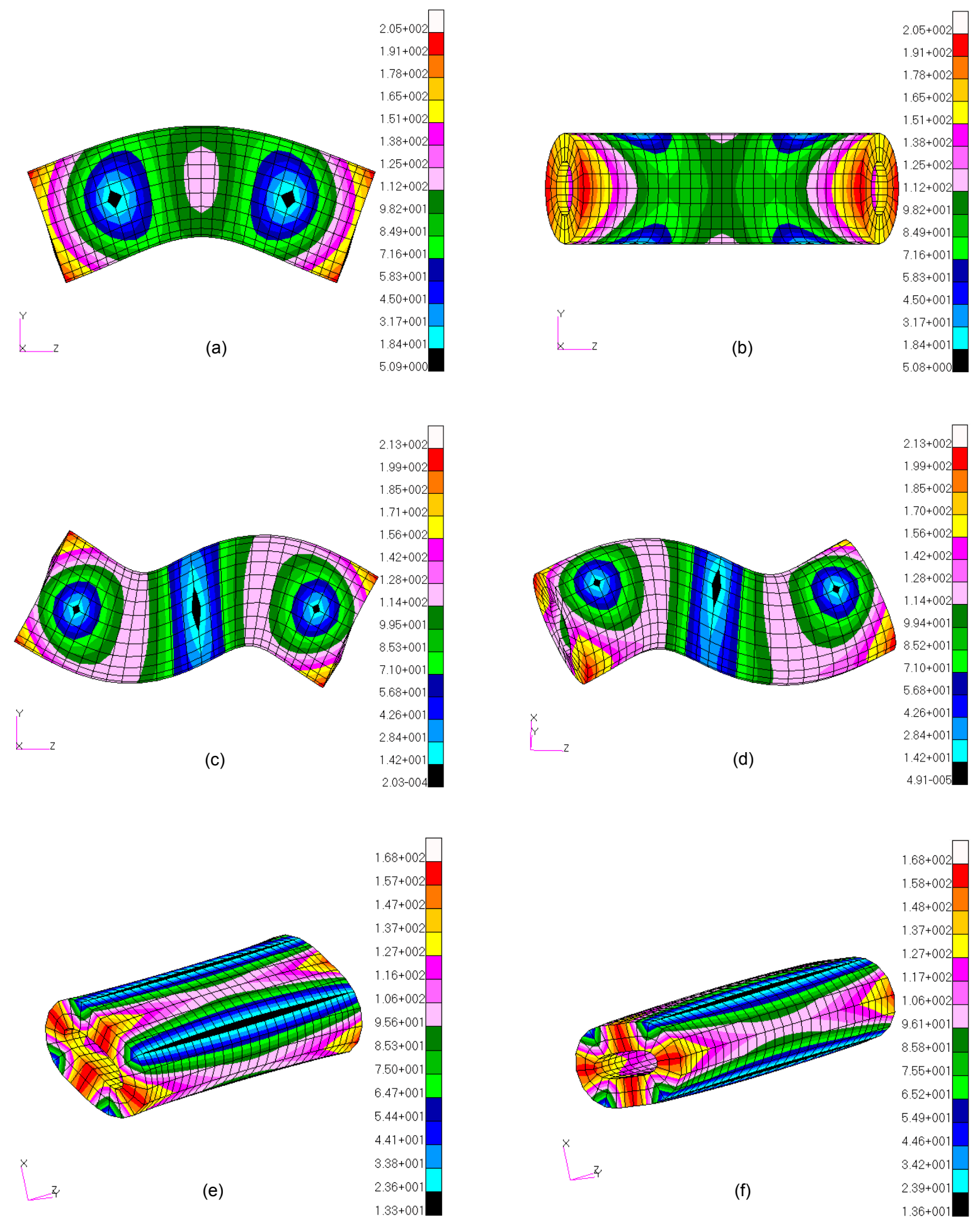

Fig. A1 The first six mode shapes of the piston pin

(a) Mode 1, frequency=24045 Hz; (b) Mode 2, frequency=24056 Hz; (c) Mode 3, frequency=46440 Hz; (d) Mode 4, frequency $=46464 \mathrm{~Hz}$; (e) Mode 5, frequency $=51560 \mathrm{~Hz}$; (f) Mode 6 , frequency $=51632 \mathrm{~Hz}$ 